\title{
MAX MARTIN
}

\section{Redwalds Börse \\ Gewicht und Gewichtskategorien völkerwanderungszeitlicher Objekte aus Edelmetall}

Einführung, S. 206. - 1. Gewichte römischer Schmuckstücke aus Gold, S. 207. - 2. Gewichte germanischer Insignien und Schmuckstücke aus Gold, S. 212. - 3. Gewichte germanischer Schmuckstücke aus Silber, S. 220. - 4. Schluß, S. 226. - Anhang 1: Die Gewichte einiger Goldobjekte aus den Gräbern einer langobardischen Adelsfamilie bei Cividale, S. 232. - Anhang 2: Goldzahlungen und Solidihorte, S. 234.

\section{EINFÜHRUNG (s. Nachtrag S. 238)}

Als im Sommer 1939 bei Sutton Hoo in Suffolk das Schiffsgrab des 624/625 verstorbenen ostenglischen Königs Redwald freigelegt wurde, fanden sich in der königlichen Gürteltasche 37 Goldmünzen (Trienten, hauptsächlich aus dem Rhonetal und den Gebieten zwischen Loire und Rhein) sowie 3 Münzschrötlinge und 2 kleine Barren aus Gold ${ }^{1}$. Es war J. Werner, der 1981 in seinem Kommentar zum 1975 erschienenen ersten Band der Sutton Hoo-Publikation das Gesamtgewicht $(54,1121 \mathrm{~g})$ dieser 42 Goldobjekte ermittelte ${ }^{2}$. Obwohl er gleich danach die Börse des 482 bei Tournai beigesetzten fränkischen Königs Childerich, die über 100 Solidi enthalten haben muß, als immer noch beste Parallele anführte, unterließ er aber begreiflicherweise eine Umrechung des Börseninhalts von Sutton Hoo in Solidi. Denn keiner der 37 Trienten (zusammen 40,0032 g, d. h. im Mittel 1,081 g pro Stück) entspricht gewichtmäßig noch einem Drittel des seit seiner Einführung unter Konstantin dem Großen bis ins 6. Jahrhundert üblichen vollgewichtigen Solidus $\mathrm{zu} 4,54 \mathrm{~g}(=1 / 72 \text { des röm. Pfundes zu } 327,45 \mathrm{~g})^{3}$.

Nun stellen aber die 54,1121 g Gold in Redwalds Börse fast exakt (zu 99,2\%) ein Sechstel des römischen Pfundes dar, anders gesagt, zweimal eine uncia zu $27,2875 \mathrm{~g}$, die wichtigste Gewichtseinheit nach dem Pfund ${ }^{4}$. Offenbar wurde dem

1 J. P. C. Kent u. a., The Coins and the Date of Burial (Rupert Bruce-Mitford, The Sutton Hoo Ship-Burial I, London 1975, S. 578-682).

2 Joachim Werner, Das Schiffsgrab von Sutton Hoo (Germania 60, 1982, S. 193-209) S. 203.

3 Vgl. demnächst Max Martin, Zum Gewicht des römischen Pfundes (Actes de la table ronde sur argenterie du Bas-Empire et byzantine, Paris 1983, hg. von François Baratte) (im Druck).

4 Bereits Birgit Arrhenius (Medieval Archaeology 22, 1978, S. 189-195) S. 194, in ihrer Rezension des in Anm. 1 genannten Werkes, erkannte, daß das Durchschnittsgewicht der 37 Münzen und 3 Schrötlinge $40 \times 6$ siliquae (zu 1,137 g) und die 2 Barren je 24 siliquae entsprächen, zusammen also 288 siliquae ausmachen würden, weshalb der Hort aus 2 Unzen Gold bestünde. Sie maß diesem errechneten Wert jedoch keine Bedeutung bei, weil ihrer Ansicht nach alle 42 Goldobjekte der Börse als Gewichte verwendet worden sind. Da die Gewichtsabstände zwischen 36 Münzen, von 
königlichen Toten eine bestimmte Menge (vorwiegend gemünzten) Goldes mit ins Jenseits gegeben, die wohl in einem verschlossenen kleinen Beutel zu zwei Unzen (oder zwei zu je einer Unze) dem Thesaurus des Königs entnommen worden war; ähnliches muß 150 Jahre zuvor auch in Tournai geschehen sein (s. u.). Es besteht kein Anlaß, die Münzen von Sutton Hoo als Fährgeld für die Ruderer des Schiffes zu bezeichnen ${ }^{5}$ oder etwa als genormte Gewichte im Sinne von „Gewichtssteinen“

Wenn nun bei den Angelsachsen des 7. Jahrhunderts Gold nach offenbar römischer, auch in frühbyzantinischer Zeit weitergeführter Gewichtsnorm abgewogen wurde bzw. umlief, ist zu fragen, ob die germanische Bevölkerung - sei es nun auf der Insel oder auf dem Kontinent - damals erst, etwa im Gefolge eines Romanisierungsprozesses, oder nicht schon früher sich antiker (oder entsprechender eigener) Gewichtsnormen zu bedienen begann. Dieser schon wiederholt diskutierten Frage soll im folgenden anhand der Gewichte provinzialrömischer, dann germanischer Schmuckstücke nachgegangen werden, wobei auch Solidihorte des 5. Jahrhunderts und Schriftquellen, die von Tributzahlungen durch Rom und Byzanz an das Großreich der Hunnen und an germanische Staaten während des 5. und 6. Jahrhunderts berichten, zu berücksichtigen sind.

\section{GEWICHTE RÖMISCHER SCHMUCKSTÜCKE AUS GOLD}

$\mathrm{Daß}$ römisches Silbergeschirr und -besteck in aller Regel nach bestimmten runden Gewichtseinheiten (z. B. eine Platte zu 2 Pfund, ein Satz von vier Schüsseln zu insgesamt 3 Pfund) bestellt und vom Edelmetallschmied angefertigt wurden, habe ich anhand der auf Gefäßen angebrachten Gewichtsangaben und der effektiven Gewichte kürzlich - nicht als erster - hervorheben können ${ }^{7}$. Gleiches war auch beim Goldschmuck üblich, der kaum je mit Gewichtsangaben versehen ist, obgleich hier Ausnahmen vielleicht häufiger waren und nicht selten Steineinlagen es bis heute unmöglich machen, das reine Goldgewicht festzustellen.

Stellen wir die Gewichte einiger goldener Schmuckstücke (ohne Steine o. ä.) aus geschlossenen Funden, z. B. Abb. 56, zusammen (Tabelle 1) ${ }^{8}$, so zeigt sich klar,

der schwersten $(1,3878 \mathrm{~g}$ ) bis zur zweitleichtesten $(1,2194 \mathrm{~g})$, im Mittel nur $0,0048 \mathrm{~g}$ betragen, kann ich mir eine Verwendung als Gewichte nicht vorstellen.

5 Gegen diese von Phinipp Grierson (Antiquity 44, 1970, S. 14-18; 48, 1974, S. 139 f.) geäußerte These (vgl. Kent [wie Anm. 1] S. 586 f. und Hayo Vierck, Redwalds Asche [Offa 29, 1972, S. 20-49] S. 23 f.) wandte sich nebst Arrhenius (wie Anm. 4) S. 191 auch Werner (wie Anm. 2) S. 203.

6 Vgl. Anm. 4.

7 Max Martin, Besteck und Geräte. Stempel, Gewichtsangaben und Inschriften (Herbert A. CahN u. a., Der spätrömische Silberschatz von Kaiseraugst, Kt. Aargau [Basler Beiträge zur Ur- und Frühgeschichte 9] Derendingen 1984, S. 55-132, 382-392).

8 Eindeutige Bezüge zum unzialen Gewichtssystem sind in dieser und den folgenden Tabellen durch halbfetten Druck, unsichere hingegen durch ein Fragezeichen am Zeilenende gekennzeichnet. Zum Armringpaar aus Boscoreale (V 110/111) vgl, ein nicht in der Form, aber im Gewicht identisches Paar goldener Schlangenkopfarmringe im Schmuckhort von Zürich-Oetenbach: Ferdinand KelleR (Anzeiger für Schweizerische Altertumskunde 1, 1868-71, S. $87-89$ Taf. 5 [82,7 g+81,6 g]); ERNST Meyer, Zürich in römischer Zeit (Emil Vogt - Ernst Meyer - Hans Conrad Peyer, Zürich von der Urzeit zum Mittelalter, Zürich 1971, S. 105-162) S. 130 f. Abb. 55. 
TABELLE 1:

GEWICHTE DER IN VIER RÖMERZEITLICHEN HORTFUNDEN ENTHALTENEN GRÖSSEREN SCHMUCKSTÜCKE AUS GOLD (OHNE STEINEINLAGEN O.Ä.)

Boscoreale (79 n. Chr.):

( $\mathrm{V}=\mathrm{H}$. de Villefosse, Le trésor de Boscoreale [Mon. et Mém. Acad. Inscr. et Belles-lettres 5, 1899, S. $263-274])$

V $109 \quad$ Kette

V 110/111 Paar Armringe $(82 \mathrm{~g}+82 \mathrm{~g})$

V 112/113 Paar Armringe $(67 \mathrm{~g}$ mit Füllung $+62 \mathrm{~g})$

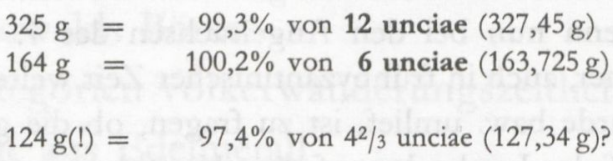

Lyon (197 n. Chr.):

(C = A. Comarmond, Description de l'écrin d'une dame romaine trouvé à Lyon en 1841, 1844)

C Taf. 1,1.2 Paar Armringe $332,5 \mathrm{~g}=101,5 \%$ von 12 unciae $(327,45 \mathrm{~g})$ $(168,3 \mathrm{~g}+164,2 \mathrm{~g})$

C Taf. 3,5.6 Paar Armringe $(33,03 \mathrm{~g}+32,0 \mathrm{~g})$

C Taf. 2,3.4 Paar Armringe $(28,2 \mathrm{~g}+26,5 \mathrm{~g})$

C Taf. 3,7 Armring $65,03 \mathrm{~g}=102,1 \%$ von $2^{1} / 3$ unciae $(63,67 \mathrm{~g})$

$54,7 \mathrm{~g}=100,2 \%$ von 2 unciae $(54,575 \mathrm{~g})$

$18,2 \mathrm{~g}=100,1 \%$ von $2 / 3$ unciae $(18,19 \mathrm{~g})$

Kastell Vemania bei Isny (t.p. 302/3 n. Chr.):

( $\mathrm{G}=\mathrm{J}$. Garbsch [Germania 49, 1971, S. $137 \mathrm{ff}]$.

G 9 Armring (eines $\quad 30,396 \mathrm{~g}=95,5 \%$ von $11 / 6$ uncia $(31,835 \mathrm{~g})$ ? Paares?)

G 2 Kette $27,8 \mathrm{~g}=101,9 \%$ von 1 uncia $(27,2875 \mathrm{~g})$

G 1 Kette $18,4 \mathrm{~g}=101,2 \%$ von $2 / 3$ uncia $(18,19 \mathrm{~g})$

G 3 Bulla (mit organi- $\quad(9,65 \mathrm{~g})=106,1 \%$ von $1 / 3$ uncia $(9,09 \mathrm{~g})$ schem Material)

G 20 Paar Ohrringe $3,4 \mathrm{~g}(!)=99,7 \%$ von $1 / 8$ uncia $(3,411 \mathrm{~g})$ ? $(1,8 \mathrm{~g}$ mit Stein $+1,7 \mathrm{~g})$

Thetford (früheres 5. Jahrhundert n. Chr.):

(JP = C. Johns - T. Potter, The Thetford Treasure, 1983)

\begin{tabular}{|c|c|c|c|}
\hline JP 26 & Armring & $108,1 \mathrm{~g}=$ & $99,0 \%$ von 4 unciae $(109,15 \mathrm{~g})$ \\
\hline JP $24 / 25$ & $\begin{array}{l}\text { Paar Armringe } \\
(26,8 \mathrm{~g}+25,9 \mathrm{~g})\end{array}$ & $52,7 \mathrm{~g}=$ & $96,6 \%$ von 2 unciae $(54,575 \mathrm{~g})$ \\
\hline JP $35 / 36$ & Kette & $28,6 \mathrm{~g}=$ & $104,8 \%$ von 1 uncia $(27,2875 \mathrm{~g})$ \\
\hline 31 & $\begin{array}{l}\text { Kette (mit } 4 \text { Glas- } \\
\text { perlen) }\end{array}$ & $18,4 \mathrm{~g}=$ & $101,2 \%$ von $2 / 3$ uncia $(18,19 \mathrm{~g})$ \\
\hline 27 & $\begin{array}{l}\text { Armring (mit noch } \\
4 \text { von einst } 26 \\
\text { Steineinlagen) }\end{array}$ & $17,8 \mathrm{~g}=$ & $97,9 \%$ von $2 / 3$ uncia $(18,19 \mathrm{~g})$ \\
\hline 32 & Kette & $17,2 \mathrm{~g}=$ & $94,6 \%$ von $2 / 3$ uncia $(18,19 g)$ \\
\hline 2 & Bulla & $13,3 \mathrm{~g}=$ & $97,5 \%$ von $1 / 2$ uncia $(13,644 \mathrm{~g})$ \\
\hline
\end{tabular}

wie Armringe (einzeln oder als Paar), Halsketten und anderes mit ihren Gewichten oft ganzen Unzen oder Teilen einer Unze entsprechen, Besteller und Hersteller sich also über die Gewichtskategorie oder eben das exakte Gewicht geeinigt hatten. 
TABELLE 2:

GEWICHTE GOLDENER ZWIEBELKNOPFFIBELN DES 4. UND 5. JAHRHUNDERTS

B = V. Bierbrauer, Die ostgotischen Grab- und Schatzfunde in Italien (1975).

$\mathrm{D}=$ D. I. Dimitrov (Bulletin de la Société archéologique à Varna 11, 1960) S. 97 Abb. 3.

DP = A. Dimitrova - Z. Popov (Thracia 4, 1977) S. 251 Abb. 18.

$\mathrm{Ha}=$ Fr. Hahn, Der Fund von Lengerich, 1854. Vgl. C. Ahrens (Hg.), Sachsen und Angelsachsen (Veröffentlichungen des Helms-Museums 32) Hamburg 1978, Kat. Nr. 12 Farbtaf. B.

$\mathrm{He}=\mathrm{J}$. Heurgon, Le trésor de Ténès, 1958.

$\mathrm{K}=\mathrm{A}$. Kiss (Acta archaeologica Acad. scient. Hungar. 38, 1986) S. 123.

$\mathrm{M}=\mathrm{F}$. H. Marshall, Catalogue of the Jewellery Greek Etruscan and Roman in the Departments of Antiquities British Museum, 1911.

$\mathrm{N} 1=\mathrm{R}$. Noll, Vom Altertum zum Mittelalter (Führer durch das Kunsthistorische Museum 8) Wien 1958.

N $2=$ R. Noll (Bonner Jahrbücher 174, 1974) S. $221 \mathrm{ff}$.

N 3 = R. Noll (Bonner Jahrbücher 176, 1976) S. $179 \mathrm{ff}$.

\begin{tabular}{|c|c|c|c|c|c|}
\hline D & Réka Devnia (L. 8,4 cm) & $167,5 \mathrm{~g}$ & $=$ & $102,3 \%$ von 6 unciae & $25 \mathrm{~g})=1 / 2$ Pfund \\
\hline e Taf. 2,1 & Ténès $(\mathrm{L} .10,5 \mathrm{~cm})$ & $81,5 \mathrm{~g}$ & $=$ & $99,6 \%$ von 3 unciae & $(81,863 \mathrm{~g})=1 / 4$ Pfund \\
\hline $1 / \mathrm{H} 4$ & Starčevo (L. $8,8 \mathrm{~cm}$ ) & $79,3 \mathrm{~g}$ & $=$ & $96,9 \%$ von 3 unciae & $(81,863 \mathrm{~g})=1 / 4$ Pfund \\
\hline 858 & Odiham (L. $7,7 \mathrm{~cm}$ ) & $61,43 \mathrm{~g}$ & $=$ & $93,8 \%$ von $22 / 5$ unciae & $(65,49 \mathrm{~g})=1 / 5$ Pfund \\
\hline / B 5 & Italien? (L. $7,0 \mathrm{~cm}$ ) & $60,7 \mathrm{~g}$ & $=$ & $92,7 \%$ von $22 / 5$ unciae & $(65,49 \mathrm{~g})=1 / 5$ Pfund \\
\hline / D 1 & Petrijanec (L. $6,1 \mathrm{~cm})$ & $54,7 \mathrm{~g}$ & $=$ & $100,2 \%$ von 2 unciae & $(54,575 \mathrm{~g})=1 / 6$ Pfund \\
\hline & Apahida I (L. $11,5 \mathrm{~cm})$ & $54,29 \mathrm{~g}$ & $=$ & $99,5 \%$ von 2 unciae & $(54,575 \mathrm{~g})=1 / 6$ Pfund \\
\hline 56 & Trier? (L. 7,5 cm) & $54,02 \mathrm{~g}$ & $=$ & $99,0 \%$ von 2 unciae & $(54,575 \mathrm{~g})=1 / 6$ Pfund \\
\hline & Lengerich $(\mathrm{L} .7,5 \mathrm{~cm})$ & $53,13 \mathrm{~g}$ & $\begin{array}{l}= \\
(=\end{array}$ & $\begin{array}{l}97,4 \% \text { von } 2 \text { unciae } \\
93,5 \% \text { von } 2^{1 / 12} \text { unciae }\end{array}$ & $\begin{array}{l}(54,575 \mathrm{~g})=1 / 6 \text { Pfund } \\
56,849 \mathrm{~g}, \text { vgl. S. } 212)\end{array}$ \\
\hline & Arezzo $(\mathrm{L} .7,0 \mathrm{~cm})$ & $52,6 \mathrm{~g}$ & $=$ & $96,4 \%$ von 2 unciae & $(54,575 \mathrm{~g})=1 / 6$ Pfund \\
\hline B 4 & Italien? (leicht fragm.) & $50,4 \mathrm{~g}$ & $=$ & $92,3 \%$ von 2 unciae & $(54,575 \mathrm{~g})=1 / 6$ Pfund \\
\hline D 2 & Petrijanec (L. $6,0 \mathrm{~cm}$ ) & $41,4 \mathrm{~g}$ & $=$ & $101,1 \%$ von $1 \frac{1}{2}$ uncia & $(40,93 \mathrm{~g})=1 / 8$ Pfund? \\
\hline & Jambol $(\mathrm{L} .8 \mathrm{~cm})$ & $38,4 \mathrm{~g}$ & $=$ & $93,8 \%$ von $1 \frac{1}{2}$ uncia & $(40,93 \mathrm{~g})=1 / 8$ Pfund? \\
\hline Taf. 2,2 & Ténès (L. 7,6 cm) & $34,5 \mathrm{~g}$ & $=$ & $94,8 \%$ von $11 / 3$ uncia & $(36,383 \mathrm{~g})=1 / 9$ Pfund? \\
\hline 5,2 & Rom, Palatin (L. $10 \mathrm{~cm})$ & $32 \mathrm{~g}$ & $=$ & $97,7 \%$ von $1 / \frac{1}{5}$ uncia & $(32,745 \mathrm{~g})=1 / 10$ Pfund \\
\hline 32,6 & Reggio Emilia (L. $8 \mathrm{~cm}$ ) & $31,87 \mathrm{~g}$ & $=$ & $97,3 \%$ von $1 \frac{1}{5}$ uncia & $(32,745 \mathrm{~g})=1 / 10$ Pfund \\
\hline 7,4 & Desana $($ L. $7,3 \mathrm{~cm})$ & $30,3 \mathrm{~g}$ & $=$ & $92,5 \%$ von $1 \frac{1}{5}$ uncia & $(32,745 \mathrm{~g})=1 / 10$ Pfund \\
\hline / B 3 . & $\begin{array}{l}\text { Fundort unbekannt } \\
\text { (L. } 4,8 \mathrm{~cm} \text {, leicht fragm.) }\end{array}$ & $26,3 \mathrm{~g}$ & $=$ & $96,4 \%$ von 1 uncia & $(27,2875 \mathrm{~g})=1 / 12$ Pfund? \\
\hline 141 & $\begin{array}{l}\text { Fundort unbekannt } \\
\text { (L. } 10,5 \mathrm{~cm} \text { ) }\end{array}$ & $20,6 \mathrm{~g}$ & $=$ & $100,7 \%$ von $3 / 4$ uncia & $(20,466 \mathrm{~g})=1 / 16$ Pfund? \\
\hline
\end{tabular}

$\mathrm{Daß}$ zu allen Zeiten nicht nur Silberlöffel ${ }^{9}$, sondern auch goldene Armbänder ein und derselben Form in unterschiedlich schweren Ausführungen auf dem Markt waren, ist kaum zu bezweifeln. Mehrere Objekte der in Tabelle 1 angeführten Schmuckhorte weisen ein Gewicht von ganzen Unzen oder Teilen davon auf. Welchen Gewichtskategorien die Fingerringe angehören, die in allen der vier Horte vertreten sind, ließe sich wegen der geringen Gewichte (meist unter $10 \mathrm{~g}$ ) und der nicht seltenen Einlagen (Gemme, Glasfluß usw.) mit Hilfe einer größeren Serie vielleicht eruieren.

\footnotetext{
9 Martin (wie Anm. 7) S. 86 Anm. 81.
} 


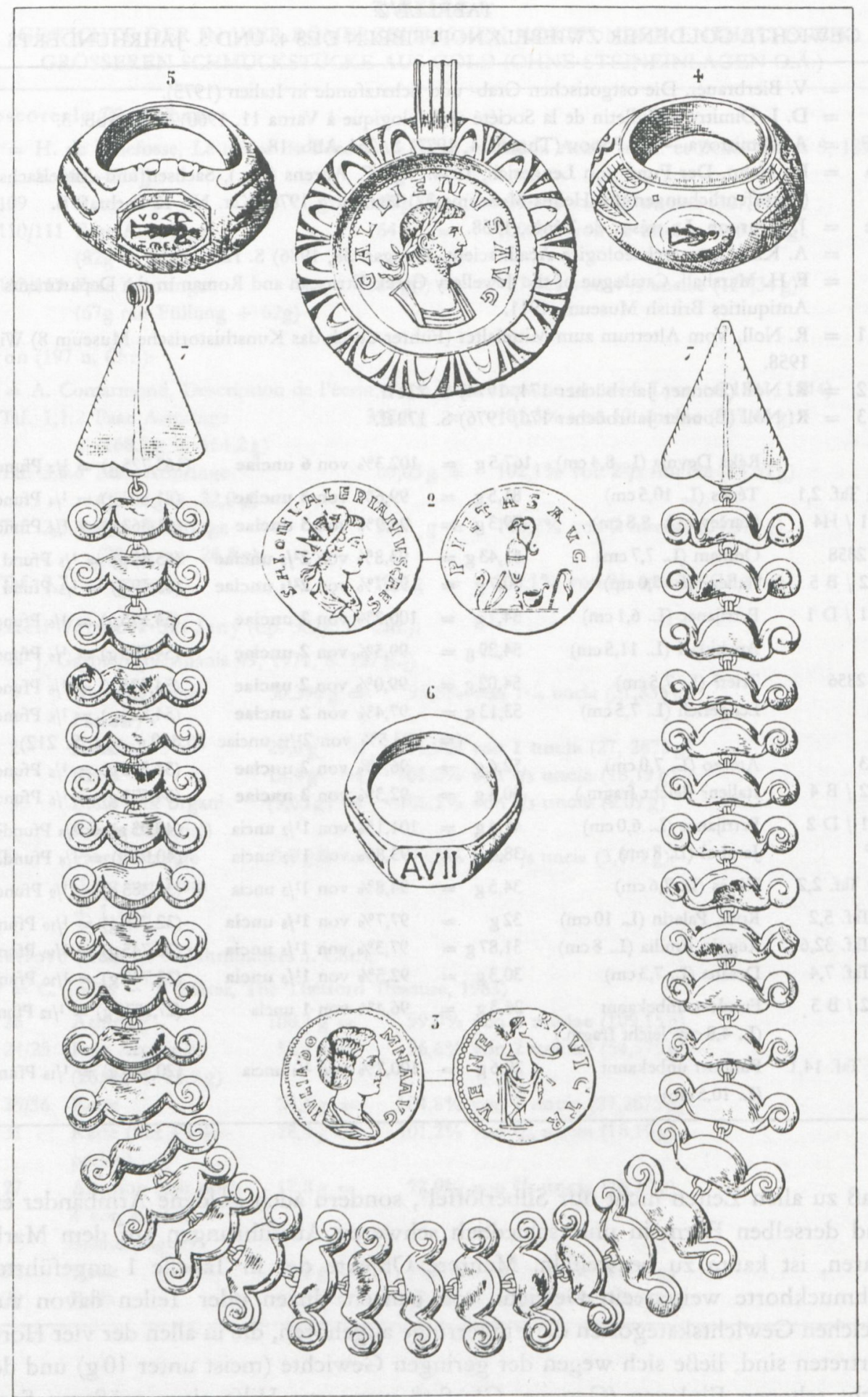

Fig. 1 Sault-Brénaz (Dép. Ain): Halskette und andere Schmuckstücke aus Gold sowie Münzen aus einem Hortfund des 3. Jahrhunderts (Schlußmünzen des Postumus, 259-268). 1:1. Vgl. Anm. 10. 


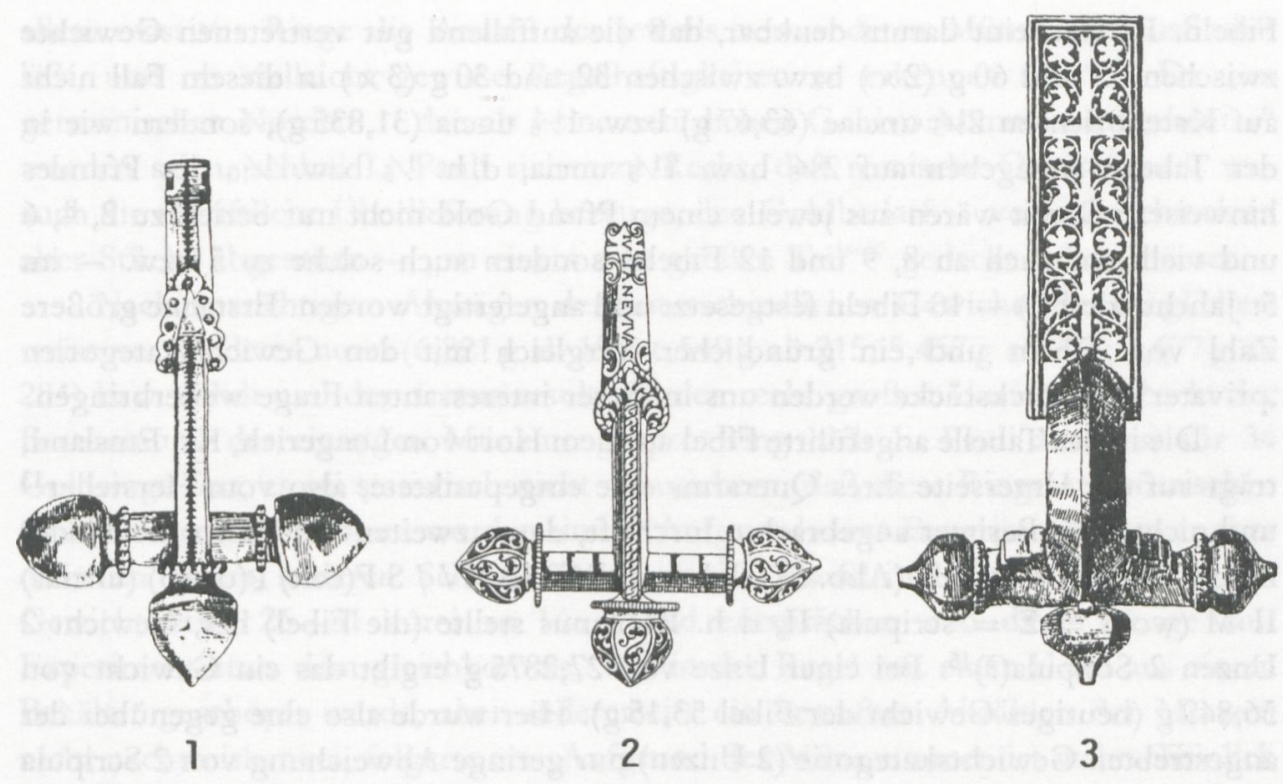

Fig. 2 Goldene Zwiebelknopffibeln: 1 aus Odiham (Hantshire), 2 aus Italien (?) (sog. Julianus-Fibel im Kunsthistorischen Museum Wien), 3 vom Palatin in Rom. 2:3. Nachweise Tabelle 2 und Anm. 11.

Drei verwandte Halsketten mit getriebenen Gliedern in Blätterform aus drei Schatzfunden des mittleren Drittels des 3. Jahrhunderts verraten mit ihrem Gewicht - in Kaiseraugst (Kt. Aargau) $29 \mathrm{~g}$, in Sault-Brénaz (Dép. Ain) (Fig. 1) $26 \mathrm{~g}$, in Szalacska (Kom. Somogy) $25 \mathrm{~g}^{10}-$, daß sie zu den sicher weitverbreiteten Serien einunziger Goldketten gehörten. Mag auch bereits beim Verkauf der Ketten jede von ihnen nicht exakt 27,2875 gewogen haben und nach dem tatsächlichen Gewicht bezahlt worden sein: über die Gewichtskategorie bestand jedenfalls kein Zweifel.

Auch goldene Zwiebelknopffibeln des 4. und 5. Jahrhunderts (Fig. 2) ${ }^{11}$ halten sich mit ihren Gewichten an das römische Gewichtssystem (Tabelle 2) ${ }^{12}$. Da derartige Fibeln vom Kaiser als Rangabzeichen verliehen wurden, waren Besteller und Hersteller gewissermaßen identisch: der Staat bestimmte, ähnlich wie bei den Münzen, jeweils das Gewicht der zweifellos in ansehnlicher Zahl hergestellten

\footnotetext{
10 Kaiseraugst: Teodora Tomasevic-Buck, Ausgrabungen in Augst und Kaiseraugst 1980 (Jahresberichte aus Augst und Kaiseraugst 5, 1985, S. 239-295) S. 265-276 Abb. 35, 36 (29 g). - SaultBrénaz: Jules Charvet, Notice sur des monnaies et bijoux antiques découverts en 1862 au Sault du Rhône, Paris 1863, Taf. (26 g); Adrien Blanchet, Les trésors de monnaies romaines et les invasions germaniques en Gaule, Paris 1900, S. 175 f. (Nr. 300); für frdl. Hinweise und Hilfe bei der Beschaffung der Vorlage zu Fig. 1 danke ich B. Deppert und U. von Freeden, Frankfurt a. M. - Szalacska: Kálmán Darnay (Archaeologiai Ertesitö 31, 1911, S. 311-328 Taf. 1,1. [25 g]).

11 Die Fibel aus Odiham (Fig. 2,1) hier nach Guide to the Antiquities of Roman Britain, hg. von R. L. S. Bruce-Mrtford, London 31964, S. 20, Abb. 10, 28, die Fibeln im Kunsthistorischen Museum Wien (Fig. 2,2) und vom Palatin in Rom (Fig. 2,3) nach Alors RIEGL, Spätrömische Kunstindustrie, Wien 21927, Abb. 68.71 wiedergegeben.

12 Die Angaben zu den noch nicht veröffentlichten Gewichten der Fibeln von Lengerich und von unbekanntem Fundort verdanke ich H.-J. Hässler, Hannover, und F. Baratte, Paris.
} 
Fibeln. Es erscheint darum denkbar, daß die auffallend gut vertretenen Gewichte zwischen 65 und $60 \mathrm{~g}(2 \times)$ bzw. zwischen 32 und $30 \mathrm{~g}(3 \times)$ in diesem Fall nicht auf Kategorien zu 21/3 unciae $(63,67 \mathrm{~g})$ bzw. $11 / 6$ uncia $(31,835 \mathrm{~g})$, sondern wie in der Tabelle angegeben auf $22 / 5$ bzw. $11 / 5$ uncia, d. h. $1 / 5$ bzw. 1/10 des Pfundes hinweisen: Damit wären aus jeweils einem Pfund Gold nicht nur Serien zu 2, 4, 6 und vielleicht auch zu 8, 9 und 12 Fibeln, sondern auch solche zu 5 bzw. - im 5. Jahrhundert $(!)-10$ Fibeln festgesetzt und angefertigt worden. Erst eine größere Zahl von Fibeln und ein gründlicher Vergleich mit den Gewichtskategorien ,privater' Schmuckstücke werden uns in dieser interessanten Frage weiterbringen.

Die in der Tabelle angeführte Fibel aus dem Hort von Lengerich, Kr. Emsland, trägt auf der Unterseite ihres Querarms eine eingepunktete, also vom Hersteller ${ }^{13}$ und nicht vom Besitzer angebrachte Inschrift, deren zweiter Teil bisher nicht oder falsch ${ }^{14}$ aufgelöst wurde (Abb. 57). Ich lese: ROMANV / S F(ecit) $\mathrm{P}$ (ondo) (uncias) II $\mathrm{M}$ (wohl $=\Sigma=$ scripula) II, d. h. Romanus stellte (die Fibel) her, Gewicht 2 Unzen 2 Scripula(?) ${ }^{15}$. Bei einer Unze von 27,2875 g ergibt das ein Gewicht von $56,849 \mathrm{~g}$ (heutiges Gewicht der Fibel 53,15 g). Hier wurde also eine gegenüber der angestrebten Gewichtskategorie (2 Unzen) nur geringe Abweichung von 2 Scripula ( $=2 / 24$ unciae $=2,274 \mathrm{~g}=4,2 \%$ über dem Sollgewicht) festgehalten.

\section{GEWICHTE GERMANISCHER INSIGNIEN UND SCHMUCKSTÜCKE AUS GOLD}

In einem Anhang zu J. Werners 1980 erschienener Abhandlung über kaiserzeitliche und frühmittelalterliche Handgelenkringe aus Gold in reichen germanischen Männergräbern hatte L. Pauli versucht zu klären, „ob sich in den Gewichten vor

13 Vgl. dazu Martin (wie Anm. 7) S. 382 ff. und Ders. bei Michel. Feugère, Le trésor d'argenterie gallo-romaine de Thil (Haute-Garonne) dit ,trésor de Caubiac‘ (Actes de la table ronde sur argenterie du Bas-Empire et byzantine [wie Anm. 3] im Druck).

14 Gustav Behrens, Römische Fibeln mit Inschrift (Reinecke-Festschrift, Mainz 1950, S. $11 \mathrm{f}$. und Abb. 14,3) las „ROMANV ... ERME“ und merkte an, daß die „vollständige Lesung der Inschrift ... bisher noch nicht gelungen“ sei. Bei Albert Genrich, Die Altsachsen, Hildesheim 1981, S. 80 findet sich die Lesung „ROMANUS F REM“, „nach Alföldi zu deuten: Dieses Stück fertigte Romanus für die Remer“. Gesamthaft gesehen stand Fr. HAHN, Der Fund von Lengerich, Hannover 1854, dem Inhalt und Sinn der Inschrift näher, als er in seiner Erstveröffentlichung schrieb, daß sich „mit Sicherheit nur ROMANVS lesen“ lasse, um fortzufahren: „Außerdem sind noch ein M und ein P, so wie einige undeutliche Figuren zu erkennen. Es scheint fast, daß diese Inschrift nur zur Bezeichnung des Fabrikanten gedient habe“ (ebd. S. 35). - Für freundliche Auskunft und Zusendung von Fotos habe ich H.-J. Hässler und St. Veil, Niedersächsisches Landesmuseum Hannover, sehr zu danken.

$15 \mathrm{Ob}$ M II am Ende der Inschrift wirklich 2 scripula bedeuten, wie ich annehme, ist nicht so entscheidend wie die richtige Lesung des ersten Zeichens nach dem unbestrittenen ROMANU / S $\mathrm{F}$ (ecit): Der nachfolgende Buchstabe ist kein $\mathrm{R}$, da er sich vom ersten Buchstaben der Inschrift eindeutig unterscheidet. Man erkennt auf Fotos ein klares P, an dessen Unterteil von rechts zwei Punkte eines ,Querstrichs' stoßen, der wegen Abnutzung (?) der Kante des Fibelquerarms heute wohl wie auch das unterste Ende des $\mathrm{P}$ beschädigt bzw. unvollständig ist. Zu derartigen $\mathrm{P}$, die durch Querstrich als Abkürzung für P(ondo) gekennzeichnet sind, vgl. z. B. MArtin (wie Anm. 7) S. 382 ff. und Abb. 148. Zum P mit Querstrich und zur Gewichtsangabe der Scripula vgl. grundlegend bereits Theodor Mommsen (Hermes 3, 1869, S. 469-475) und Ders., Gesammelte Schriften 7, Berlin 1909, S. $774 \mathrm{ff} ., 780 \mathrm{f}$. 
allem massiver Ringe die Anzahl der jeweils verwendeten Münzen herausfinden läßt, und ob vielleicht gewisse Regelhaftigkeiten zu erkennen sind“ 16 . Da „im germanischen Norden ... damals keine natürlichen Goldvorkommen ausgebeutet“ worden seien, schloß L. Pauli sicher zu Recht, daß römische Goldmünzen, was auch die schriftliche Überlieferung bezeuge, den Goldbedarf - vom Umschmelzen alter Stücke abgesehen - „zu einem sehr großen Teil“17 gedeckt haben müssen.

Nach vorsichtigem Abwägen der unterschiedlichen Gewichte der möglicherweise verwendeten aurei $(6,821 \mathrm{~g}$ ab $193 ; 6,549 \mathrm{~g}$ ab $215 ; 5,457 \mathrm{~g}$ ab $238 ; 4,677 \mathrm{~g}$ ab 284) bzw. solidi und der daraus resultierenden recht großen Unsicherheiten in der Bestimmung der einstigen Münzmenge pro Ring hielt L. Pauli zunächst für 34 Goldringe fest, es sei statistisch nicht abzusichern, daß diese Ringe aus römischen Goldmünzen erschmolzen worden sind ${ }^{18}$. Aufgrund eines Experiments kam er aber dann zu einem anderen Schluß: Da einerseits Zweidrittel der Ringe in ihrem Gewicht etwa 26-31 aurei zu 1/60 Pfund entsprächen und diese Menge laut Experiment etwa dem gleichkomme, was in der Regel mit einer Hand aus einem Behälter geschöpft werde, aber andererseits ein bewußtes Abzählen der Münzen nicht nachweisbar sei, folgerte er: „Aufgrund der Münzsummen ist wahrscheinlich ein größerer Teil der Schlangenkopfarmringe aus römischen aurei erschmolzen worden ... In Anbetracht der frühgeschichtlichen Verhältnisse auf wirtschaftlichem und sozialem Gebiet ist am ehesten anzunehmen, daß der rex oder princeps als Stifter der Ehrenringe eine Handvoll Goldmünzen aus seinem Vorrat entnahm, wobei dieser Geste mehr Bedeutung zukam als der tatsächlichen Anzahl der - im Rahmen gewisser Grenzen - zufällig ergriffenen Münzen."19

Dieser These sei im folgenden widersprochen: Auch wenn selbstverständlich sehr oft Goldmünzen das Material für germanische (und römische) Schmuckstücke abgegeben haben mögen ${ }^{20}$, weshalb J. Werner schon seit einiger Zeit für germanische Goldobjekte der Völkerwanderungszeit die Anzahl der verwendeten Solidi berechnet ${ }^{21}$, ist doch darauf hinzuweisen, daß in erster Linie - und interessanterweise nicht nur im Innern des Imperium Romanum - vom Gewicht selbst auszugehen und nach den damals üblichen Gewichten und Gewichtseinheiten zu fragen ist. Wenn spätrömische und frühmittelalterliche Schmuckstücke im Gewicht beispielsweise 4 bzw. 27 Solidi schwer sind, hängt dies eben damit zusammen, daß der Solidus ein Sechstel, d. h. eine sextula $(4,5479 \mathrm{~g})$ einer uncia $(27,2875 \mathrm{~g})$ wiegt, womit 4 bzw. 27 Solidi gewichtsmäßig eben $2 / 3$ bzw. 41/2 Unzen entsprechen.

16 Ludwig Pauli, Römische Münzen und germanische Schlangenkopfarmringe (JoAchim Werner, Der goldene Armring des Frankenkönigs Childerich und die germanischen Handgelenkringe der jüngeren Kaiserzeit [Frühmittelalterliche Studien 14, 1980, S. 1-49] S. 41-49) bes. S. 41.

17 Pauli (wie Anm. 16) S. 41.

18 Ebd. S. 47.

19 Ebd. S. 49.

20 Oft dürften auch Barren und bereits früher verarbeitetes Gold (Altgold) als Rohmaterial gedient haben, so wie etwa in der Börse von Sutton Hoo das ungemünzte Gold 20\% der Gesamtmenge ausmacht.

21 Vgl. JoAchim Werner, Die frühgeschichtlichen Grabfunde vom Spielberg bei Erlbach, Ldkr. Nördlingen, und von Fürst, Ldkr. Laufen a.d. Salzach (Bayerische Vorgeschichtsblätter 25, 1960, S. 164-179) S. $171 \mathrm{ff}$. und Ders. (wie Anm. 16) S. $1 \mathrm{ff}$. 
Vergleichen wir nun die Gewichte der von L. Pauli untersuchten 34 Schlangenkopfarmringe mit dem römischen Gewichtssystem, so ergibt sich folgendes (Fig. 3) ${ }^{22}$ : Die drei schwersten Ringe wiegen noch zu fast $100 \%$ (99,79\% bzw. $99,62 \%$ bzw. 99,92\%) $81 / 3$ unciae (Nr. 15), 8 unciae (Nr. 1) und $7 \frac{1}{2}$ unciae (Nr. 9) des römischen Gewichtssystems. Auf vier weitere, ursprünglich vielleicht $71 / 3$ Unzen schwere Exemplare folgen - in markantem Abstand - fünf Ringe (Nr. 2, 3, 17, $18,20)$, deren Gewichte nur sehr geringfügig voneinander differieren $(191,71 \mathrm{~g}-$ 191,25 g; Mittel 191,476 g) ${ }^{23}$. Im Gegensatz zu L. Paulis Schluß ${ }^{24}$ wird durch Fig. 3 deutlich, daß diese Ringe, die zusammen mit einem sechsten Exemplar (Nr. 31) durchschnittlich 191,38 g wiegen, mit einem leichten Übergewicht $(100,19 \%)$ je 7 römische Unzen $(191,0125 \mathrm{~g})$ schwer sind. Auf diese Ringserie folgen, nach neun unterschiedlich schweren Stücken, wiederum vier untereinander fast gleich schwere Ringe (Nr. 32, 7, 19, 11: $182 \mathrm{~g}-181,7 \mathrm{~g}$; Mittel: 181,885 g), die im Mittel noch zu 99,98\% das Gewicht von 62/3 Unzen $(181,916 \mathrm{~g})$ aufweisen.

Ohne auf die gewichtsmäßig nicht nach Unzen und Sextulae meßbaren Stücke einzugehen ${ }^{25}$, ist doch aufgrund der drei schwersten Armringe und der beiden Ringserien zu 7 bzw. 62/3 Unzen erwiesen, daß Schlangenkopfarmringe in aller Regel nach dem römischen oder einem diesem entsprechenden germanischen Gewichtssystem hergestellt und gewogen wurden. Der Goldschmied bekam also für die Herstellung eines Ringes keineswegs etwa eine „Handvoll“ römischer Goldmünzen von nicht exakt bestimmter Anzahl, womit sich die von L. Pauli daran geknüpften Gedanken erübrigen ${ }^{26}$.

Erst nach Abfassen des vorigen Abschnitts kam mir die Arbeit F. Herschends über die Gewichte und Gewichtseinheiten der auf Öland gefundenen völkerwanderungszeitlichen Goldobjekte (94 Spiralgoldteile, 77 Fingerringe, 18 Armringe, 10

22 Die in Fig. 3 unten angegebenen Nummern der 34 Ringe entsprechen den Nummern bei WERNER (wie Anm. 16) S. 40 f.; ihre Anordnung zeigt, daß die schweren Ringe vor allem in Schweden vorkommen. Weitere Ringe, die Werner, S. 28 Anm. 98 nicht hatte überprüfen können, nannte u. a. Gustaf Kossinna (Mannus 14, 1922, S. 131 ff.): a) Vestra Rickeby 2 Exemplare zu 191,3 g (= $100,2 \%$ von 7 Unzen); b) Paboda 202,2 g (=?); c) Krakelund $180 \mathrm{~g}$ (=62/3 Unzen?).

23 Roger Blidmo, Statens Historiska Museum Stockholm, hatte im August 1982 die Freundlichkeit, die Gewichte dieser fünf Ringe (Genauigkeit 1/10 g) speziell zu überprüfen (in Klammern die Differenz zu den 1891 veröffentlichten Wägungen H. Hildebrands): Nr. 2: 191,7 g (+0,2 g). - Nr.

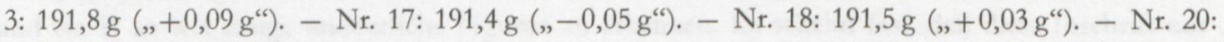
$192,0 \mathrm{~g}(+0,75 \mathrm{~g})$. - In unserer Fig. 3 sind für diese wie auch andere Ringe die auf H. Hildebrand und anderen Autoren beruhenden Gewichtsangaben J. Werners beibehalten. - Vgl. jetzt zwei Gewichtslisten bei Herschend (wie Anm. 27) S. 238 ff. Fig. 31 und 32, leider ohne Angabe der Fundorte bzw. Inventarnummern.

${ }^{24}$ Pauli (wie Anm. 16) S. 47 glaubte, daß für diese Fünferserie „allein eine Münzsumme von 41 Aurei zu 1/70 libra in Frage kommt ... Da diese Aurei erst ab 284 geprägt wurden, wäre die chronologische Konsequenz für diese Ringe und ihre Beifunde zu überprüfen."

25 Es wären überhaupt alle Ringe, auch die gewichtsmäßig ,passenden', durch Autopsie auf ihren Erhaltungszustand zu überprüfen.

26 Wenn nordische Sagen von 'baugenreichen' Fürsten oder Herrschern berichten, möchte man annehmen, daß den Gefolgsleuten fertige Baugen geschenkt oder verliehen wurden. In den betreffenden Thesauri wird man Gold, außer in Münzform, auch verarbeitet zu Ringen und Spiralgold aufbewahrt haben. 


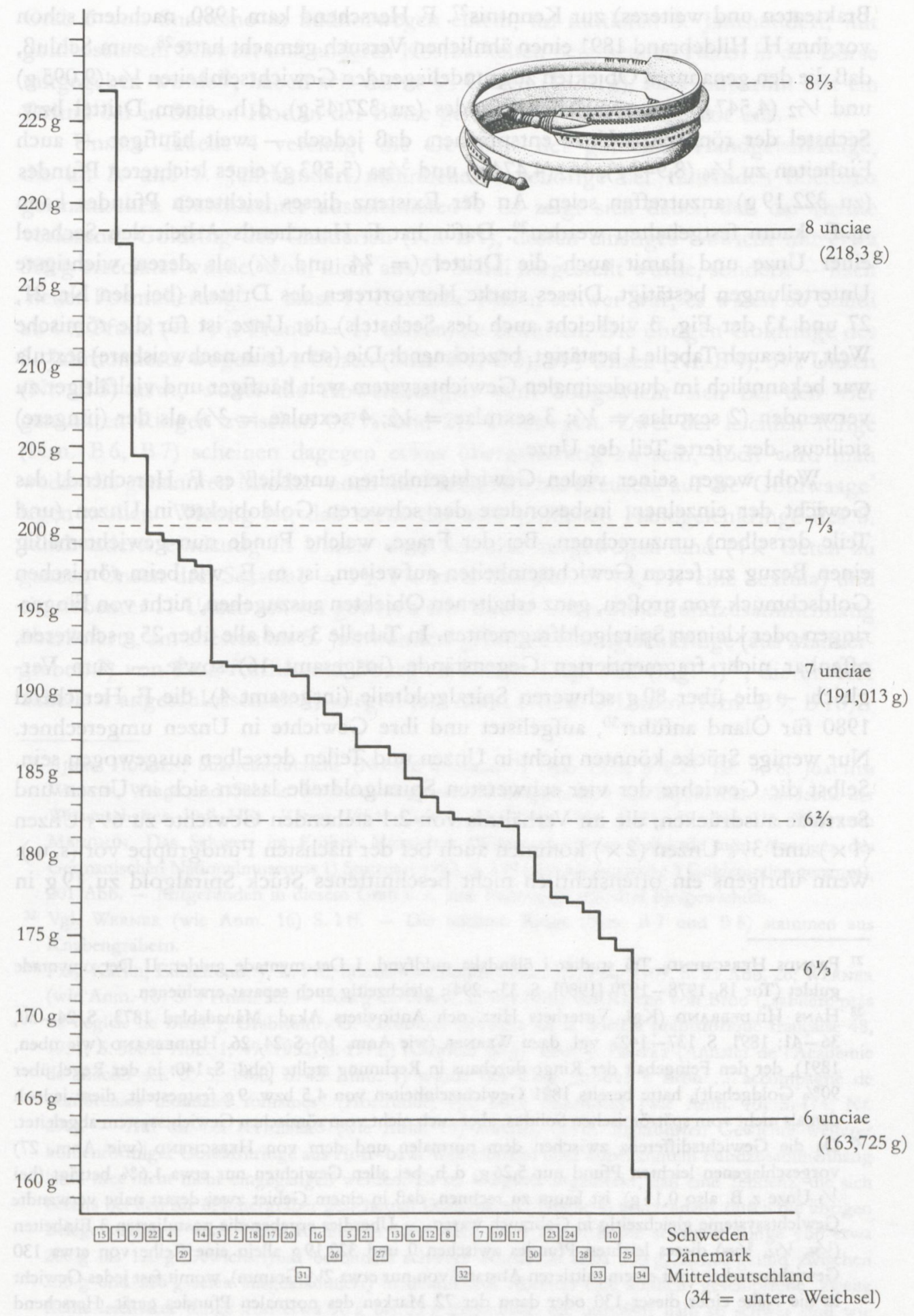

Fig. 3 Gewichte von 34 germanischen Schlangenkopfarmringen aus Gold (in Gramm bzw. Unzen). Zusammenstellung und Gewichte nach J. Werner, 1980, vgl. Anm. 16. 
Brakteaten und weiteres) zur Kenntnis ${ }^{27}$. F. Herschend kam 1980, nachdem schon vor ihm H. Hildebrand 1891 einen ähnlichen Versuch gemacht hatte ${ }^{28}$, zum Schluß, $\mathrm{da}$ die den genannten Objekten zugrundeliegenden Gewichtseinheiten 1/36 (9,095 g) und $1 / 72(4,547 \mathrm{~g}$ ) des römischen Pfundes (zu 327,45 g), d. h. einem Drittel bzw. Sechstel der römischen Unze entsprächen, daß jedoch - weit häufiger - auch Einheiten zu 1/36 (8,949 g), 1/72 (4,474 g) und 5/288 (5,593 g) eines leichteren Pfundes (zu 322,19g) anzutreffen seien. An der Existenz dieses leichteren Pfundes kann m. E. kaum festgehalten werden ${ }^{29}$. Dafür hat F. Herschends Arbeit den Sechstel einer Unze und damit auch die Drittel (= $2 / 6$ und $4 / 6$ ) als deren wichtigste Unterteilungen bestätigt. Dieses starke Hervortreten des Drittels (bei den Nr. 21, 27 und 13 der Fig. 3 vielleicht auch des Sechstels) der Unze ist für die römische Welt, wie auch Tabelle 1 bestätigt, bezeichnend: Die (sehr früh nachweisbare) sextula war bekanntlich im duodezimalen Gewichtssystem weit häufiger und vielfältiger zu verwenden $(2$ sextulae $=1 / 3 ; 3$ sextulae $=1 / 2 ; 4$ sextulae $=2 / 3)$ als der (jüngere) sicilicus, der vierte Teil der Unze.

Wohl wegen seiner vielen Gewichtseinheiten unterließ es F. Herschend, das Gewicht der einzelnen, insbesondere der schweren Goldobjekte in Unzen (und Teile derselben) umzurechnen. Bei der Frage, welche Funde nun gewichtsmäßig einen Bezug zu festen Gewichtseinheiten aufweisen, ist $\mathrm{m}$. E. wie beim römischen Goldschmuck von großen, ganz erhaltenen Objekten auszugehen, nicht von Fingerringen oder kleinen Spiralgoldfragmenten. In Tabelle 3 sind alle über $25 \mathrm{~g}$ schweren, offenbar nicht fragmentierten Gegenstände (insgesamt 16) sowie - zum Vergleich - die über $80 \mathrm{~g}$ schweren Spiralgoldteile (insgesamt 4), die F. Herschend 1980 für Öland anführt ${ }^{30}$, aufgelistet und ihre Gewichte in Unzen umgerechnet. Nur wenige Stücke könnten nicht in Unzen und Teilen derselben ausgewogen sein. Selbst die Gewichte der vier schwersten Spiralgoldteile lassen sich in Unzen und Sextulae ausdrücken; die im Verhältnis von 2:1 stehenden Gewichte zu 61/3 Unzen $(1 \times)$ und $31 / 6$ Unzen $(2 \times)$ kommen auch bei der nächsten Fundgruppe vor (s. u.). Wenn übrigens ein offensichtlich nicht beschnittenes Stück Spiralgold zu $19 \mathrm{~g}$ in

${ }^{27}$ Frands Herschend, Trå studier i öländska guldfynd. I Det myntade guldet, II Det omyntade guldet (Tor 18, 1978-1979 [1980], S. 33-294); gleichzeitig auch separat erschienen.

28 Hans Hildebrand (Kgl. Vitterhets Hist. och Antiqvitets Akad. Månadsblad 1873, S. 24-30, 36-41; 1891, S. 137-142); vgl. dazu Werner (wie Anm. 16) S. 24, 26. Hilddebrand (wie oben, 1891), der den Feingehalt der Ringe durchaus in Rechnung stellte (ebd. S. 140: in der Regel über $90 \%$ Goldgehalt), hatte bereits 1891 Gewichtseinheiten von 4,5 bzw. $9 \mathrm{~g}$ festgestellt, diese jedoch damals nicht vom spätrömischen Solidus, aber auch nicht vom römischen Gewichtssystem abgeleitet.

$29 \mathrm{Da}$ die Gewichtsdifferenz zwischen dem normalen und dem von Herschend (wie Anm. 27) vorgeschlagenen leichten Pfund nur 5,26 g, d. h. bei allen Gewichten nur etwa 1,6\% beträgt (bei $1 / 3$ Unze z. B. also $0,15 \mathrm{~g}$ ), ist kaum zu rechnen, daß in einem Gebiet zwei derart nahe verwandte Gewichtssysteme gleichzeitig in Gebrauch waren. - Überdies ergeben die postulierten 3 Einheiten $(1 / 36,1 / 72,5 / 288)$ dieses leichten Pfundes zwischen 0 und $322,19 \mathrm{~g}$ allein eine Reihe von etwa 130 Gewichtsmarken (mit einem mittleren Abstand von nur etwa $2 \frac{1}{2}$ Gramm), womit fast jedes Gewicht in die Nähe einer dieser 130 oder dann der 72 Marken des normalen Pfundes gerät. Herschend rechnet darum überall mit Abweichungen von weniger als $1 \%$ vom ursprünglichen Gewicht. Gegen die Annahme differierender Pfundgewichte während der römischen Kaiserzeit vgl. Martin (wie Anm. 3).

30 Herschend (wie Anm. 27) S. $280 \mathrm{ff}$. 
Grab 5 von Snartemo in Südnorwegen einem, im mittleren 5. Jahrhundert, mit goldbesetztem Schwert und anderen Kostbarkeiten beigesetzten Herrn in der Börse mitgegeben wurde ${ }^{31}$, haben wir damit $2 / 3$ Unzen $(18,19 \mathrm{~g})$, also immerhin fast ein Drittel der in Sutton Hoo in der Börse gefundenen Goldmenge vor uns.

Unsere Tabelle 4 vereinigt die Gewichte der goldenen Handgelenkringe, die im 3. und 5. Jahrhundert männliche Angehörige der führenden höchsten germanischen Geschlechter auszeichneten ${ }^{32}$. Es zeigt sich dabei, daß der (heute verlorene) Goldring des Childerich (Nr. B 1), dessen einstiges Gewicht mit etwa $300 \mathrm{~g}$ errechnet wurde, wohl nicht aus 67 Solidi hergestellt wurde, sondern - nach 'neuer Formulierung' - einst 11 römische Unzen schwer war; es wären 66 Solidi zu $1 / 72$ Pfund $(=11 / 12$ Pfund $=11$ Unzen) zu erwarten. Die übrigen Goldringe des 5. Jahrhunderts wogen $81 / 2$ Unzen (Nrn. B 2, B 3), 61/3 Unzen (Nr. B 4), 31/6 Unzen (Nr. B5) usw., wobei die Abweichungen vom Sollgewicht sich bei den vier genannten Ringen zwischen $0,7 \%$ und $2,3 \%$ bewegen. Zwei der leichten Ringe (Nrn. B 6, B 7) scheinen dagegen etwas übergewichtig zu sein, doch wird man weder die genannten Minder- noch die Mehrgewichte allzusehr auf die 'Goldwaage' legen wollen. Wichtig ist, daß sechs der acht goldenen Handgelenkringe des 5. Jahrhunderts eindeutig in Unzen und Sextulae ausgewogen sind $(4 \times$ treten zu ganzen Unzen drei Sextulae $=1 / 2,1 \times$ zwei Sextulae $=1 / 3,1 \times$ eine Sextula) und ein siebenter 11 Unzen schwer gewesen sein dürfte. Zwei ohne Fundzusammenhang überlieferte, am ehesten ins 5. Jahrhundert gehörige Handgelenkringe (aus Männergräbern?) von Prag-Karlín und Bourg-en-Bresse, Dép. Ain (Fig. 4) ${ }^{33}$, die unserer Tabelle 4 angeschlossen sind, wiegen fast exakt 6 bzw. 3 Unzen (Nrn. B 9, B 10).

31 Bjørn Hougen, Snartemofunnene (Norske Oldfunn 7) Oslo 1935, S. 8,15 Taf. 4, 8; Joachim WERnER, Waage und Geld in der Merowingerzeit (Sitzungsberichte der Bayerischen Akademie der Wissenschaften Phil.-Hist. Klasse 1954, Heft 1) München 1954, S. 21, 39 (Nr. 71); Wilfried Menghin, Das Schwert im Frühen Mittelalter (Wissenschaftliche Beibände zum Anzeiger des Germanischen Nationalmuseums 1) Stuttgart 1983, S. 199 (fälschlicherweise 3 Goldspiralen genannt), $201 \mathrm{Abb}$. - Mitgefunden in diesem Grab u. a. eine Feinwaage mit drei Bleigewichten.

32 Vgl. Werner (wie Anm. 16) S. 1 ff. - Die leichten Ringe (Nrn. B 7 und B 8) stammen aus Knabengräbern.

33 Prag-Karlín, Einzelfund: J. L. PíC, Starožitnosti země České 3,1, Prag 1909, S. 53 Abb. 26; Werner (wie Anm. 16) S. 9 Anm. 30. - Bourg-en-Bresse, in der Nähe der Kirche von Brou („,sablière près de l'église de Brou“), Grabfund?: G. Gaudron (Bulletin de la Société préhistorique française 48, 1951, S. 566 f. Abb. 1; 49, 1952, S. 197 f.) (Gewicht 80 g). Laut J. Protat (Annales de l'Académie de Mâcon sér. 3, 5, 1900, S. 43 Anm. 1) wurde der Ring „trouvé à Brou ... accompagné de nombreuses monnaies romaines" (Hortfund?; vgl. noch Blanchet [wie Anm. 10] S. 174, Nr. 296). - Auf die bei Kyhlberg (wie Anm. 73) S. $66 \mathrm{ff} ., 118 \mathrm{ff}$. angeführten Gewichte weiterer kolbenförmiger Goldarmringe aus Hort- bzw. Weihefunden oder unbekanntem Fundzusammenhang kann hier nicht mehr eingegangen werden. Es sei lediglich angemerkt, daß eine Tendenz, die sich bereits bei den für Männergräber gesicherten Exemplaren (Tabelle 4) abzeichnete, durch die übrigen Belege verstärkt wird: Nach Kyhlbergs Liste steht einer ersten Reihe schwerer Ringe von etwa $200 \mathrm{~g}$ bis $120 \mathrm{~g}$ Gewicht (fünf besonders schwere Stücke zu etwa $300 \mathrm{~g}, 284,00 \mathrm{~g}$ und zwischen $235 \mathrm{~g}$ und $226 \mathrm{~g}$ seien ausgeklammert) in deutlichem Abstand eine ähnlich 'geschlossene' zweite Reihe leichterer Ringe von etwa $90 \mathrm{~g}$ bis $53 \mathrm{~g}$ gegenüber, die ungefähr halb so schwer sind wie erstere und nur als Paar deren Gewicht erreichen (würden); von fünf nochmals leichteren, zwischen $46 \mathrm{~g}$ und $20 \mathrm{~g}$ schweren Ringen stammen zwei bezeichnenderweise aus Knabengräbern (Tabelle 4, B 7 und B 8). - Vor kurzem wies KARL HauCK (Frühmittelalterliche Studien 19, 1985, S. 190-194) auf die Gewichte der beiden Kolbenarmringe und des Spiralarmrings aus dem Goldfund von 
TABELLE 3:

GEWICHTE ALLER AUF ÖLAND GEFUNDENEN ÜBER $25 \mathrm{~g}$ SCHWEREN VOLLSTÄNDIGEN GOLDOBJEKTE (AUSSER SCHLANGENKOPFARMRINGEN) UND ÜBER $80 \mathrm{~g}$ SCHWEREN SPIRALGOLDTEILE

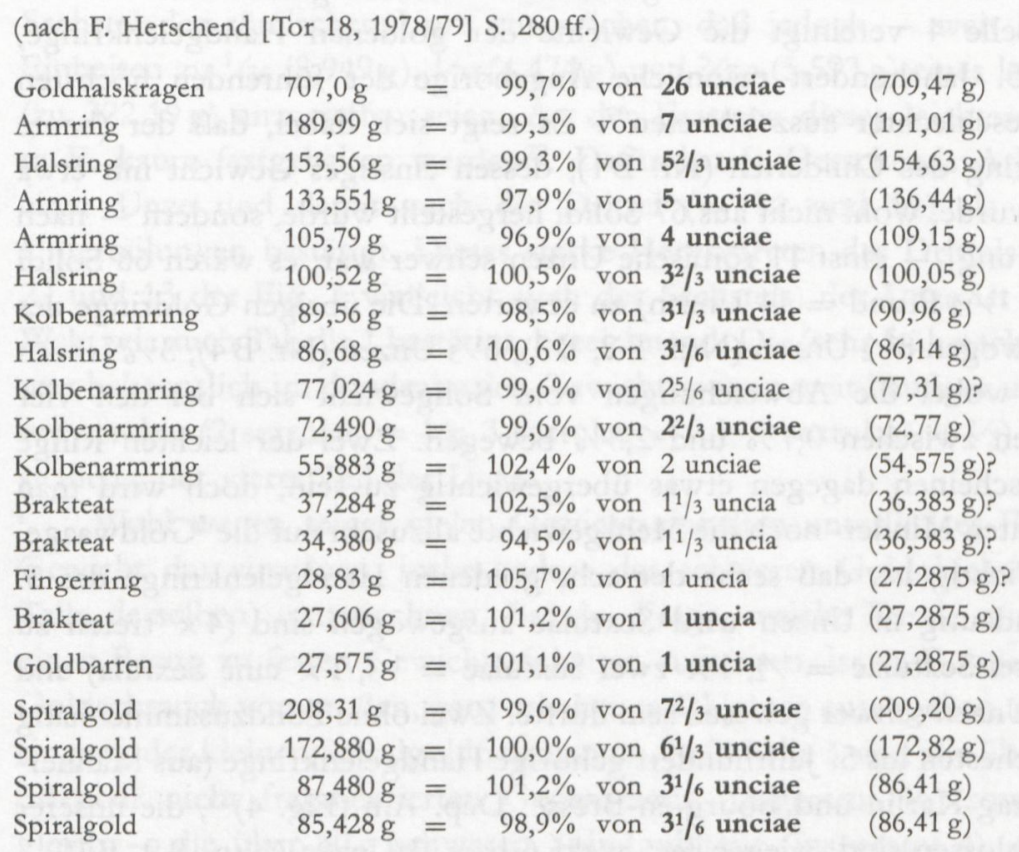

TABELLE 4:

GEWICHTE DER GOLDENEN HANDGELENKRINGE AUS GERMANISCHEN MÄNNERGRÄBERN

(vgl. J. Werner [Frühmittelalterl. Studien 14, 1980] S. 1 ff. Tabellen 1 und 3; zu B 9 und B 10 vgl. Anm. 33)

3. Jahrhundert:

A 1 Pielgrzymowo

A 2 Cejkov

A 3 Zakrzów (Grab 1)

A 4 Ostroviany (Grab 1)

A 5 Ostroviany (Grab 2)

A 6 Himlingöje 1894

A 7 Grabow

A 8 Zakrzów (Grab 3)

5. Jahrhundert:

B 1 Tournai

B 2 Apahida

B 3 Blučina

B 4 Pouan

B 5 Wolfsheim

B 6 Fürst

B 7 Großörner

B 8 Mezöberény

$$
\begin{aligned}
& 235 \mathrm{~g}=\quad 99,4 \% \text { von } 8^{2} / 3 \text { unciae }(236,489 \mathrm{~g}) \\
& 200,7 \mathrm{~g}=100,3 \% \text { von } 71 / 3 \text { unciae }(200,11 \mathrm{~g}) \\
& 196,8 \mathrm{~g}=\quad 98,3 \% \text { von } 71 / 3 \text { unciae }(200,11 \mathrm{~g}) ? \\
& 191,5 \mathrm{~g}=100,3 \% \text { von } 7 \text { unciae }(191,01 \mathrm{~g}) \\
& 184,59 \mathrm{~g}=99,0 \% \text { von } 65 / 6 \text { unciae }(186,46 \mathrm{~g}) ? \\
& 169 \mathrm{~g}=97,8 \% \text { von } 61 / 3 \text { unciae }(172,82 \mathrm{~g}) ? \\
& 140 \mathrm{~g}=99,3 \% \text { von } 5^{1} / 6 \text { unciae }(140,98 \mathrm{~g}) \\
& 72,5 \mathrm{~g}=99,6 \% \text { von } 2^{2} / 3 \text { unciae }(72,58 \mathrm{~g})
\end{aligned}
$$

$$
\begin{aligned}
& \text { etwa } 300 \mathrm{~g}=(99,9 \%) \text { von } 11 \text { unciae }(300,16 \mathrm{~g}) \\
& 230,20 \mathrm{~g}=99,3 \% \text { von } \mathbf{8} \mathbf{1} / \mathbf{2} \text { unciae }(231,94 \mathrm{~g}) \\
& 226,70 \mathrm{~g}=97,7 \% \text { von } \mathbf{8} 1 / 2 \text { unciae }(231,94 \mathrm{~g}) \\
& 171,00 \mathrm{~g}=99,0 \% \text { von } \mathbf{6}^{\mathbf{1}} / \mathbf{3} \text { unciae }(172,82 \mathrm{~g}) \\
& 85,05 \mathrm{~g}=98,4 \% \text { von } 31 / 6 \text { unciae }(86,41 \mathrm{~g}) \\
& 69,16 \mathrm{~g}=101,4 \% \text { von } 2 \frac{1}{2} \text { unciae }(68,22 \mathrm{~g}) \\
& 41,64 \mathrm{~g}=101,7 \% \text { von } 1 \frac{1}{2} \text { uncia }(40,93 \mathrm{~g}) \\
& 32,50 \mathrm{~g}=102,1 \% \text { von } 11 / 6 \text { uncia }(31,84 \mathrm{~g}) \text { ? }
\end{aligned}
$$


vermutlich zu dieser Serie gehörend:
B 9 Prag-Karlín
$160,682 \mathrm{~g}=$
$98,1 \%$ von 6 unciae $(163,725 \mathrm{~g})$
B 10 Bourg-en-Bresse
$80 \mathrm{~g}=$
$97,7 \%$ von 3 unciae $(81,863 \mathrm{~g})$

TABELLE 5:

GEWICHTE VON PAAREN GOLDENER HANDGELENKRINGE AUS FRAUENGRÄBERN DES 3. UND 5. JAHRHUNDERTS N. CHR.

(vgl. J. Werner [Frühmittelalterl. Studien 14, 1980] S. 12 ff. Tabelle 2)

3. Jahrhundert:

Tuna $(87 \mathrm{~g}+78,77 \mathrm{~g})$

Himlingöje (Grab 2/1949)

$165,77 \mathrm{~g}=101,2 \%$ von 6 unciae $(163,725 \mathrm{~g})$

$(59,25 \mathrm{~g}+59 \mathrm{~g})$

$118,25 \mathrm{~g}=100,0 \%$ von $41 / 3$ unciae $(118,246 \mathrm{~g})$

5. Jahrhundert:

Untersiebenbrunn $(65,3 \mathrm{~g}+63,8 \mathrm{~g}) \quad 129,1 \mathrm{~g}=94,6 \%$ von 5 unciae $(136,44 \mathrm{~g})$ ?

Von den acht Belegen des 3. Jahrhunderts sind fünf Ringe $82 / 3,71 / 3,7,61 / 3$ und $2 \frac{2}{3}$ Unzen schwer; die restlichen Stücke scheinen $71 / 3,65 / 6$ und $61 / 3$ Unzen gewogen zu haben. Bereits bei diesen Ringen des 3. Jahrhunderts überwiegen als Teilbeträge die Sextulae (einzeln, doppelt usw.), ein Beweis, daß der erst im Jahre 307 eingeführte, eine Sextula schwere Solidus auch im 4. und 5. Jahrhundert nicht für dieses häufige Teilgewicht verantwortlich gemacht werden kann.

Es fällt auf, daß offenbar erst mit den Handgelenkringen des 5. Jahrhunderts, und zwar vor allem den jüngeren dieser Reihe, nun auch die halbe Unze als Teil des Gesamtgewichts auftaucht (Tabelle 4 Nrn. B 2, B 3, B 6 und B 7), während in der römischen Welt (Tabellen 1 und 2), aber auch im völkerwanderungszeitlichen Skandinavien (Tabelle 3 und Fig. 3) zu ganzen Unzen noch fast ausnahmslos nur Drittel- und Sechstelunzen hinzukamen ${ }^{34}$. Ob Gewichte mit halben Unzen im Laufe der Zeit häufiger wurden und Teilgewichte aus Sextulae zurückdrängten, wäre zu prüfen.

Broholm auf Fünen hin. Wie bereits MunksgaArd (wie Anm. 50, 1978, S. 150f. [mit z. T.

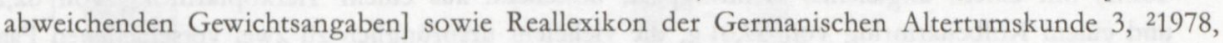
S. 470) sah, lassen sich diese Gewichte wie auch die der drei mitgefundenen Halsringe sehr gut im römischen Gewichtssystem einordnen:

$\begin{array}{lrl}\text { Kolbenarmring } & 53,00 \mathrm{~g}=97,1 \% \text { von } 2 \text { Unzen }(54,575 \mathrm{~g}) \\ \text { Kolbenarmring, fragm. } & (50,22 \mathrm{~g})=(92,0 \%) \text { von } 2 \text { Unzen }(54,575 \mathrm{~g}) \\ \text { Spiralarmring } & 52,00 \mathrm{~g}=95,3 \% \text { von } 2 \text { Unzen }(54,575 \mathrm{~g}) \\ \text { Halsring 1 } & 1364,60 \mathrm{~g}=100,0 \% \text { von } 4 \text { Pfund } 2 \text { Unzen }(1364,375 \mathrm{~g}) \\ \text { Halsring 2 } & 812,00 \mathrm{~g}=99,2 \% \text { von } 2 \text { Pfund } 6 \text { Unzen }(818,625 \mathrm{~g}) \\ \text { Halsring 3 } & 534,20 \mathrm{~g}=97,9 \% \text { von } 1 \text { Pfund } 8 \text { Unzen }(545,75 \mathrm{~g})\end{array}$

Die drei Halsringe waren übrigens, was bisher anscheinend unbeachtet blieb, den Bezug zum Unzialsystem jedoch vollends deutlich macht, 50, 30 und 20 Unzen schwer; ihr Gesamtgewicht entsprach zu 99,34\% dem Gewicht von 100 Unzen!

34 Selbst bei paarweise hergestelltem Schmuck, insbesondere bei Armringen, wurden Gesamtgewichte wie z. B. 3 oder 5 Unzen vermieden, um nicht Einzelgewichte von $1 \frac{1}{2}$ oder $21 / 2$ Unzen zu erhalten. Noch bei den Bügelfibeln des 5. und 6. Jahrhunderts gibt es offenbar Paare zu 2 oder 4 Unzen, nicht aber zu 3 Unzen, allerdings bereits eine größere Zahl von Paaren zu 1 Unze (Fig. 6-8). 


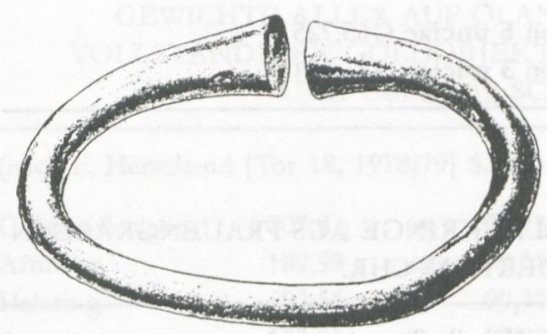

1

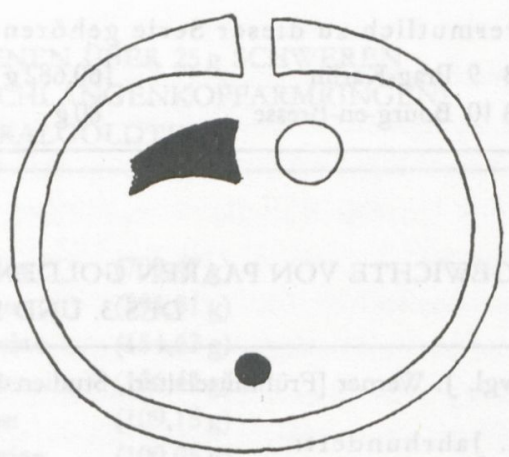

2

Fig. 4 Goldene Handgelenk(?)ringe aus Prag-Karlín (1) und Bourg-en-Bresse, Dép. Ain (2). 2:3. Nachweise Anm. 33.

Bei den von Frauen getragenen Goldarmringpaaren des 3. und 5. Jahrhunderts finden wir Gesamtgewichte von etwa 6 bis $4 \frac{1}{3}$ Unzen, was pro Armring etwa 3 bzw. $2 \frac{1}{2}$ (?) bis $2 \frac{1}{6}$ Unzen ergibt (Tabelle 5$)^{35}$.

\section{GEWICHTE GERMANISCHER SCHMUCKSTÜCKE AUS SILBER}

Als vor einigen Jahren $\mathrm{H}$. Roth in diesem Jahrbuch merowingerzeitliche Gußtiegel besprach, stellte er auch die Gewichte einiger Bügelfibelpaare und Ármringe aus Silber hauptsächlich des 6. Jahrhunderts zusammen, um ihre Volumen mit den in den Tiegeln zu schmelzenden Silbermengen vergleichen zu können ${ }^{36}$. Bereits die wenigen dort genannten Gewichte ließen einen Bezug zur römischen Unze $(27,2875 \mathrm{~g})$ und ihrem Mehrfachen erkennen, wie Fig. 6 zeigt; in diese Übersicht sind weitere 12 mir bekanntgewordene Gewichte von silbernen Bügelfibelpaaren und Armringen aufgenommen worden ${ }^{37}$. Da an Fibeln nicht selten

35 Nicht aufgenommen ist das bei Werner (wie Anm. 16) S. 14 angeführte Grab von Regöly (Kom. Tolna) mit einem ungleichen Armringpaar, bestehend aus einem Tierkopfarmring von $62,20 \mathrm{~g}$ und einem Kolbenarmring von 59,61 g, die vielleicht ursprünglich zu zwei verschiedenen Paaren gehörten.

36 Helmut Roth, Beobachtungen an merowingerzeitlichen Gußtiegeln (Frühmittelalterliche Studien 11, 1977, S. $85-91)$ S. 89 f.

${ }^{37}$ Nachweise zu den in Fig. 6 eingetragenen Gewichten von Bügelfibeln (A-C) und Armringen (D): A (Bügelfibelpaare) 1 Donzdorf Grab 78: Roтн (wie Anm. 36) S. 89 (140 g+133,5 g). - 2 Cividale A 59/60: ebd. $(128,40 \mathrm{~g}+116,25 \mathrm{~g})$. - 3 Dagersheim: ebd. $(120 \mathrm{~g}+$ fragmentiert). - 4 GrabenNeudorf Grab von 1974: JAN DER K Bosen, Ein alamannisches Frauengrab von Graben-Neudorf, Kreis Karlsruhe (Fundberichte aus Baden-Württemberg 10, 1985, S. 281-317) S. 282 ff. Abb. 3 $(56,3 \mathrm{~g}+54,7 \mathrm{~g})$. - 5 Pfullingen: Rотн (wie Anm. 36) S. 89 (55g+52 g). - 6 Alcagnano $1+2$ : Volker Bierbrauer, Alamannische Funde der frühen Ostgotenzeit aus Oberitalien (Studien zur vor- und frühgeschichtlichen Archäologie. Festschrift f. Joachim Werner, hg. von GEORG KosSACK - GüNter Ulbert, München 1974, S. 559-577) S. 559 f. Taf. $37,1.2(53 \mathrm{~g}+51,2 \mathrm{~g})$. - 7 Fellbach-Schmiden Grab 13: Helmut Roth, Ein Reihengräberfeld bei Fellbach-Schmiden, RemsMurr-Kreis (Fundberichte aus Baden-Württemberg 7, 1982, S. 491-540) S. 496 f., 515 Abb. 4 $(28,2 \mathrm{~g}+26,7 \mathrm{~g}) .-8$ Alcagnano $3+4$ : Bierbrauer (wie oben) S. 560 f. Taf. $37,3.4(27,8 \mathrm{~g}+27 \mathrm{~g})$. 


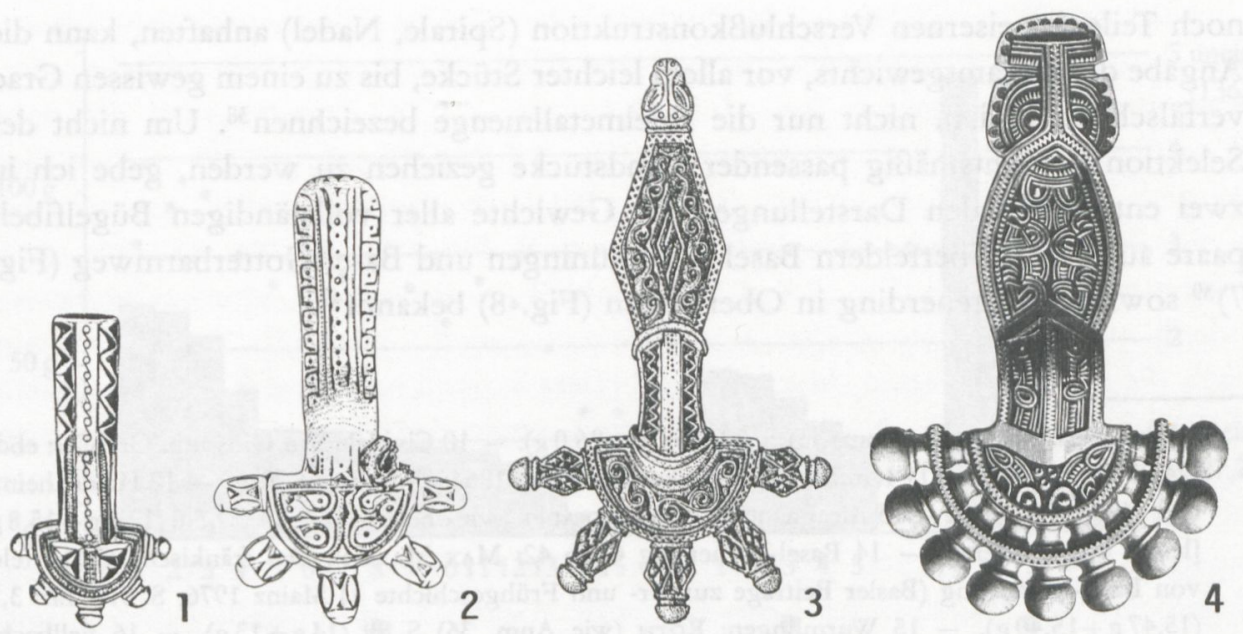

Fig. 5 Silberne Bügelfibeln (jeweils ein Exemplar eines Paares zu 1, 2, 4 bzw. 9 Unzen Gewicht) aus Fellbach-Schmiden Grab 24 (1), Fellbach-Schmiden Grab 13 (2), Graben-Neudorf Grab von 1974 (3) und Cividale A 59/60 (4). 1:2. Nachweise Anm. 37.

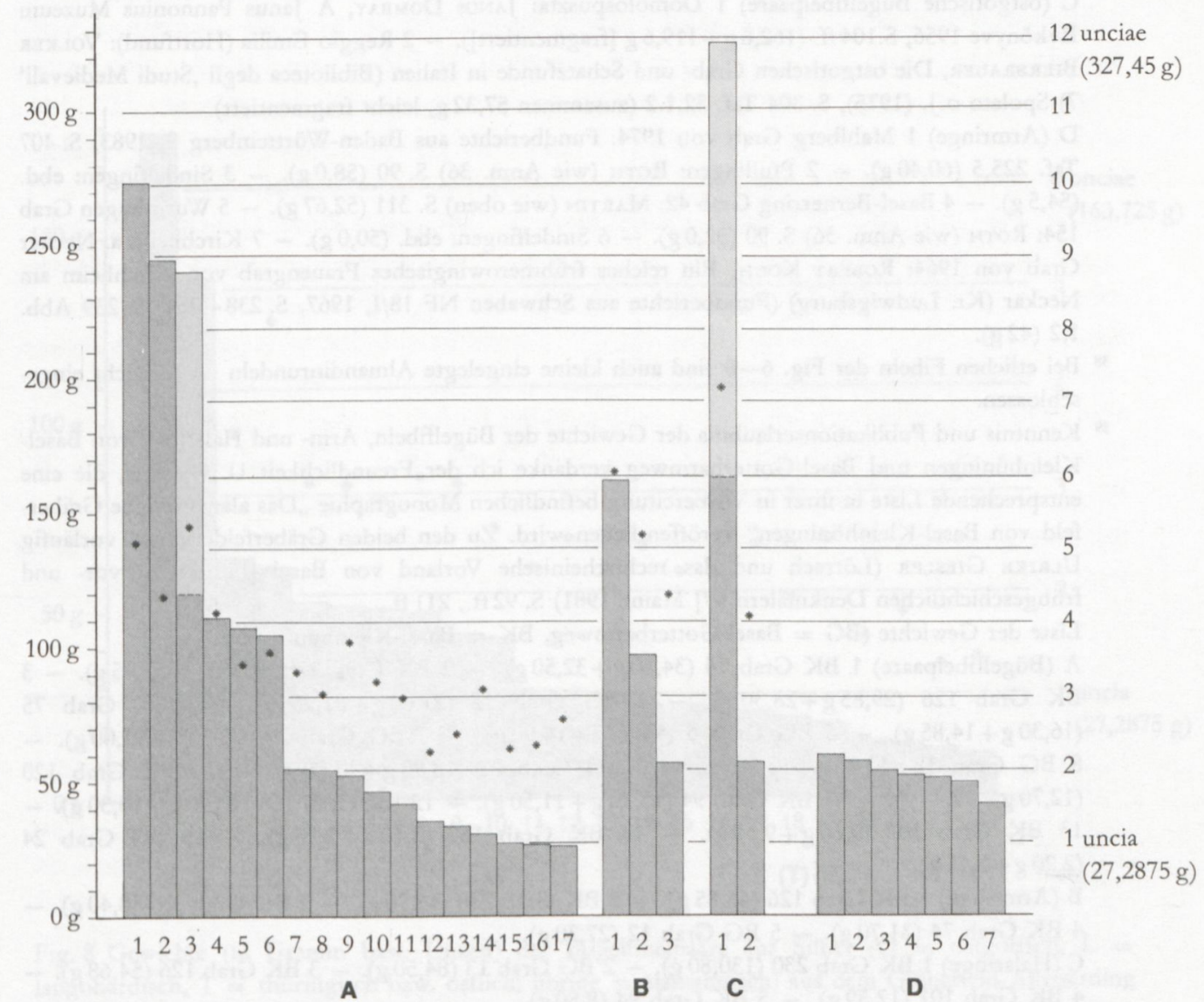

Fig. 6 Gewichte (in Gramm bzw. Unzen) weiblicher Schmuckstücke aus Silber aus alamannischen und langobardischen Grabfunden: A Bügelfibelpaare, B große, einzeln getragene Bügelfibeln nordischen Typs, C ostgotische Bügelfibelpaare (*=Gesamtlängen in mm); D Armringe. Nachweise Anm. 37. 
noch Teile der eisernen Verschlußkonstruktion (Spirale, Nadel) anhaften, kann die Angabe des Gesamtgewichts, vor allem leichter Stücke, bis zu einem gewissen Grad verfälscht sein, d.h. nicht nur die Edelmetallmenge bezeichnen ${ }^{38}$. Um nicht der Selektion gewichtsmäßig passender Fundstücke geziehen zu werden, gebe ich in zwei entsprechenden Darstellungen die Gewichte aller vollständigen Bügelfibelpaare aus den Gräberfeldern Basel-Kleinhüningen und Basel-Gotterbarmweg (Fig. 7) ${ }^{39}$ sowie aus Altenerding in Oberbayern (Fig. 8) bekannt ${ }^{40}$.

9 Ditzingen: Rotr (wie Anm. 36) S. 89 (26,5 g +26,0 g). - 10 Cividale San Giovanni Grab 32: ebd. $(24,05 \mathrm{~g}+22,90 \mathrm{~g}) .-11$ Kirchheim a. Neckar Grab von 1964: ebd. $(22 \mathrm{~g}+20 \mathrm{~g}) .-12$ Heidenheim: ebd. $(18,0 \mathrm{~g}+17,5 \mathrm{~g}) \cdot-13$ Alcagnano 5+6: Bierbrauer (wie oben) S. 561 Taf. 37,5.6 (17,6 g + 15,8 g [leicht fragmentiert]). - 14 Basel-Bernerring Grab 42: Max Martin, Das fränkische Gräberfeld von Basel-Bernerring (Basler Beiträge zur Ur- und Frühgeschichte 1) Mainz 1976, S. 311 Taf. 3,1 $(15,47 \mathrm{~g}+15,40 \mathrm{~g})$. - 15 Wurmlingen: Roтн (wie Anm. 36) S. $89(14 \mathrm{~g}+13 \mathrm{~g})$. - 16 FellbachSchmiden Grab 24: Rотн (wie oben) S. 499 f., 519 Abb. $6(13,49$ g+13,26 g). - 17 Mössingen: Rotн (wie Anm. 36) S. 89 (13,5 g+12,5 g).

B (einzeln getragene Bügelfibeln) 1 Täbingen: Roтн (wie Anm. 36) S. 89 (162 g). - 2 Kirchheim unter Teck Grab 85: ebd. (97g). - 3 Gönningen: ebd. (57 g, etwas fragmentiert).

C (ostgotische Bügelfibelpaare) 1 Domolospuszta: Janos Dombay, A Janus Pannonius Muzeum Evkönyve 1956, S.104 ff. (162,6 g+119,6 g [fragmentiert]). - 2 Reggio Emilia (Hortfund): VolKER Bierbrauer, Die ostgotischen Grab- und Schatzfunde in Italien (Biblioteca degli ,Studi Medievali ${ }^{\star}$ 7) Spoleto o.J. (1975), S. 304 Taf. 32,1.2 (zusammen 57,32 g, leicht fragmentiert).

D (Armringe) 1 Mahlberg Grab von 1974: Fundberichte aus Baden-Württemberg 8, 1983, S. 407 Taf. 225,5 (60,40 g). - 2 Pfullingen: Rотн (wie Anm. 36) S. 90 (58,0 g). - 3 Sindelfingen: ebd. (54,5 g). - 4 Basel-Bernerring Grab 42: Martin (wie oben) S. 311 (52,67 g). - 5 Wurmlingen Grab 154: Roth (wie Anm. 36) S. 90 (52,0 g). - 6 Sindelfingen: ebd. (50,0 g). - 7 Kirchheim a. Neckar Grab von 1964: RoвERт Koch, Ein reiches frühmerowingisches Frauengrab von Kirchheim am Neckar (Kr. Ludwigsburg) (Fundberichte aus Schwaben NF 18/I, 1967, S. 238-254) S. 239 Abb. $1,2(42 \mathrm{~g})$.

38 Bei etlichen Fibeln der Fig. 6-8 sind auch kleine eingelegte Almandinrundeln im Gewicht eingeschlossen.

39 Kenntnis und Publikationserlaubnis der Gewichte der Bügelfibeln, Arm- und Halsringe von BaselKleinhüningen und Basel-Gotterbarmweg verdanke ich der Freundlichkeit U. Gieslers, die eine entsprechende Liste in ihrer in Vorbereitung befindlichen Monographie „Das alamannische Gräberfeld von Basel-Kleinhüningen“" veröffentlichen wird. Zu den beiden Gräberfeldern vgl. vorläufig Ulrike Giesler (Lörrach und das rechtsrheinische Vorland von Basel [Führer zu vor- und frühgeschichtlichen Denkmälern 47] Mainz 1981) S. 92 ff., $211 \mathrm{ff}$.

Liste der Gewichte (BG = Basel-Gotterbarmweg, BK = Basel-Kleinhüningen):

A (Bügelfibelpaare) 1 BK Grab $74(34,80 g+32,50 g)$. -2 BK Grab $230(32,65 g+32,45 g)$. -3 BK Grab $126(29,85 \mathrm{~g}+28,30 \mathrm{~g})$. - 4 BG Grab $12(21,60 \mathrm{~g}+21,25 \mathrm{~g})$. - 5 BK Grab 75 $(16,30 \mathrm{~g}+14,85 \mathrm{~g})$. -6 BG Grab $6(15,80 \mathrm{~g}+14,90 \mathrm{~g})$. - 7 BG Grab $20(15,55 \mathrm{~g}+15,00 \mathrm{~g})$. 8 BG Grab $18(13,95 \mathrm{~g}+13,50 \mathrm{~g})$. - 9 BG Grab $22(13,95 \mathrm{~g}+13,00 \mathrm{~g})$. - 10 BK Grab 120 $(12,70 \mathrm{~g}+12,40 \mathrm{~g}) \cdot-11$ BK Grab $94(13,20 \mathrm{~g}+11,50 \mathrm{~g}) .-12$ BK Grab $163(10,70 \mathrm{~g}+10,30 \mathrm{~g})$. 13 BK Grab $102(9,60 \mathrm{~g}+9,50 \mathrm{~g})$. - 14 BK Grab $167(3,40 \mathrm{~g}+2,90 \mathrm{~g})$. - 15 BG Grab 24 $(2,20 \mathrm{~g}+2,15 \mathrm{~g})$.

B (Armringe) 1 BK Grab $126(46,85 \mathrm{~g})$. - 2 BK Grab $230(45,70 \mathrm{~g})$. - 3 BK Grab $35(38,40 \mathrm{~g})$. 4 BK Grab $74(31,70 \mathrm{~g})$. - 5 BG Grab $12(27,30 \mathrm{~g})$.

C (Halsringe) 1 BK Grab 230 (130,80 g). - 2 BG Grab 13 (84,50 g). - 3 BK Grab $126(54,68 \mathrm{~g})$. 4 BK Grab 101 (12,59 g). - 5 BK Grab $94(8,80 \mathrm{~g})$.

40 W. Sage verdanke ich die Erlaubnis, die Gewichte der Altenerdinger Fibeln (Walter Sage, Das Reihengräberfeld von Altenerding in Oberbayern I [Germanische Denkmäler der Völkerwanderungszeit Ser. A, 14] Berlin 1984) aufnehmen und veröffentlichen zu können. 1 Grab 192 


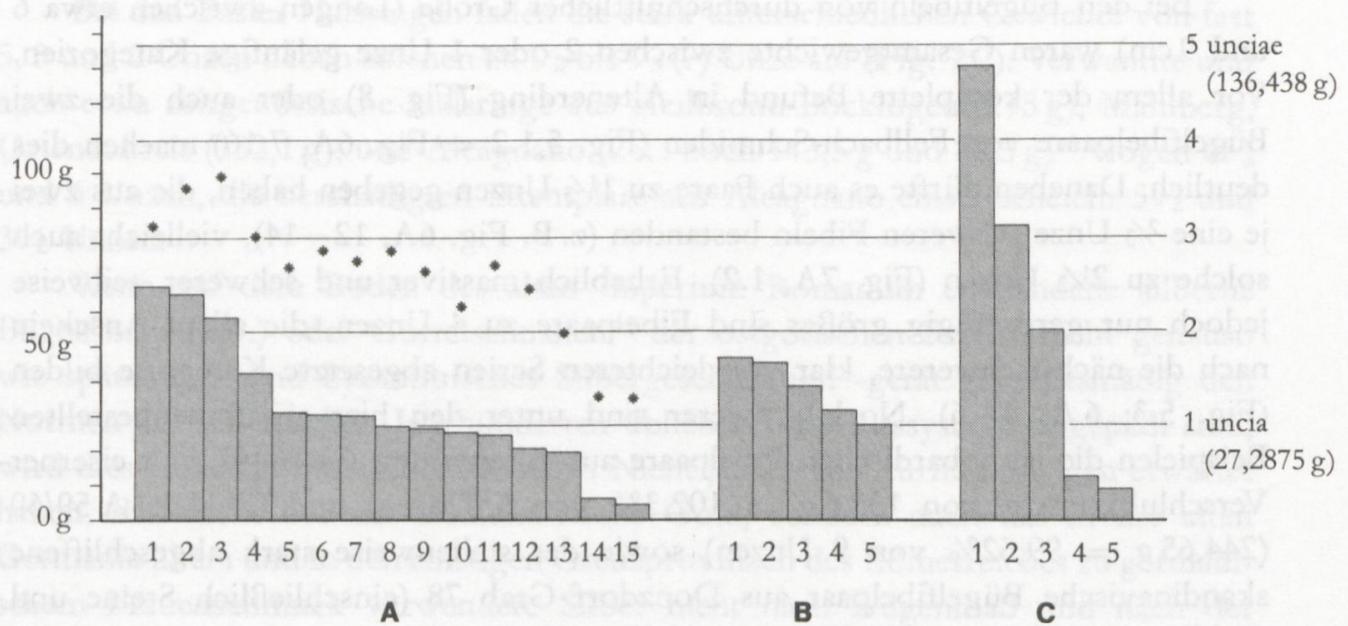

Fig. 7 Gewichte (in Gramm bzw. Unzen) weiblicher Schmuckstücke aus Silber aus den Gräberfeldern Basel-Kleinhüningen und Basel-Gotterbarmweg: A Bügelfibelpaare (* = Gesamtlängen in mm), B Armringe, C Halsringe. Nachweise Anm. 39.

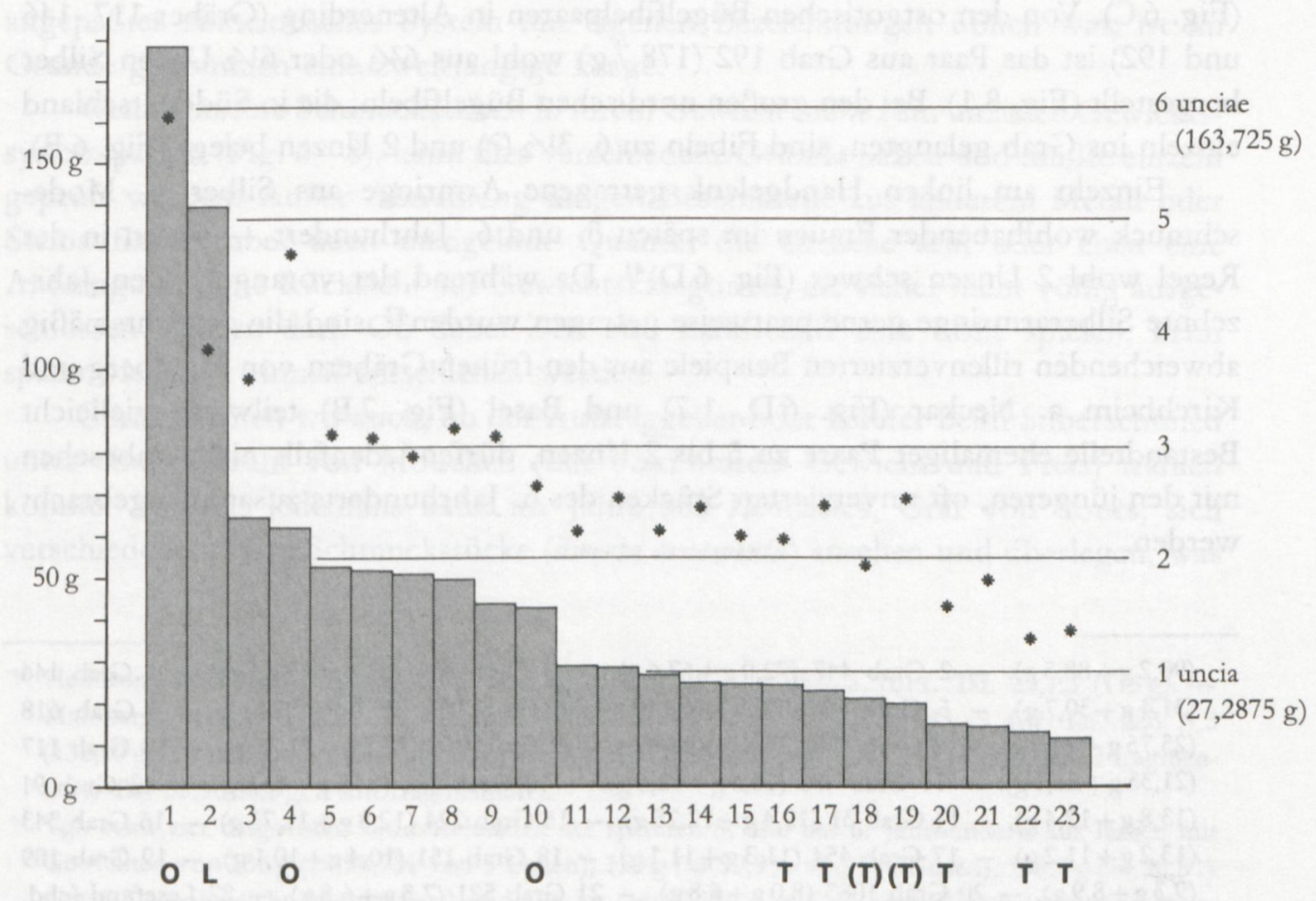

Fig. 8 Gewichte (in Gramm bzw. Unzen) der Bügelfibelpaare aus Silber $(\mathrm{O}=$ ostgotisch, $\mathrm{L}=$ langobardisch, $\mathrm{T}=$ thüringisch bzw. östlich; übrige $=$ alamannisch) aus dem Gräberfeld Altenerding $\left(^{*}=\right.$ Gesamtlängen in $\left.\mathrm{mm}\right)$. Nachweise Anm. 40. 
Bei den Bügelfibeln von durchschnittlicher Größe (Längen zwischen etwa 6 und $9 \mathrm{~cm}$ ) waren Gesamtgewichte zwischen 2 oder 1 Unze geläufige Kategorien. Vor allem der komplette Befund in Altenerding (Fig. 8) oder auch die zwei Bügelfibelpaare von Fellbach-Schmiden (Fig. 5,1.2 = Fig. 6A, 7.16) machen dies deutlich. Daneben dürfte es auch Paare zu 11/3 Unzen gegeben haben, die aus zwei je eine $2 / 3$ Unze schweren Fibeln bestanden (z. B. Fig. 6A, 12-14), vielleicht auch solche zu $2 \frac{1}{2}$ Unzen (Fig. 7A, 1.2). Erheblich massiver und schwerer, teilweise jedoch nur geringfügig größer sind Fibelpaare zu 4 Unzen, die allem Anschein nach die nächstschwerere, klar von leichteren Serien abgesetzte Kategorie bilden (Fig. 5,3; 6 A, 4-6). Noch schwerer sind unter den hier zusammengestellten Beispielen die langobardischen Fibelpaare aus Altenerding Grab 447 (mit eiserner Verschlußkonstruktion $139,6 \mathrm{~g}=102,3 \%$ von 5 Unzen) und Cividale A 59/60 $(244,65 \mathrm{~g}=99,62 \%$ von 9 Unzen) sowie das stellenweise stark abgeschliffene skandinavische Bügelfibelpaar aus Donzdorf Grab 78 (einschließlich Steine und Goldbleche 273,5 $\mathrm{g}=100,23 \%$ von 10 Unzen) (Fig. 5,4; $6 \mathrm{~A}, 1.2 ; 8,2$ ).

Ein Paar Bügelfibeln aus dem wohl ostgotischen Frauengrab etwa des dritten Viertels des 5. Jahrhunderts aus Domolospuszta (Kom. Baranya) muß laut der einen ganz erhaltenen Fibel (162,6 g) einst wohl genau 1 Pfund (12 Unzen) gewogen haben, während ein jüngeres ostgotisches Bügelfibelpaar aus dem Hortfund von Reggio Emilia mit 57,32 g nur einem Sechstel (54,575 g) des Pfundes entsprach (Fig. 6C). Von den ostgotischen Bügelfibelpaaren in Altenerding (Gräber 117, 146 und 192) ist das Paar aus Grab 192 (178,7 g) wohl aus 62/3 oder 61/2 Unzen Silber hergestellt (Fig. 8,1). Bei den großen nordischen Bügelfibeln, die in Süddeutschland einzeln ins Grab gelangten, sind Fibeln zu 6, 31/2 (?) und 2 Unzen belegt (Fig. 6 B).

Einzeln am linken Handgelenk getragene Armringe aus Silber - Modeschmuck wohlhabender Frauen im späten 5. und 6. Jahrhundert - waren in der Regel wohl 2 Unzen schwer (Fig. 6D) ${ }^{41}$. Da während der vorangehenden Jahrzehnte Silberarmringe gerne paarweise getragen wurden ${ }^{42}$, sind die gewichtsmäßig abweichenden rillenverzierten Beispiele aus den frühen Gräbern von Mahlberg und Kirchheim a. Neckar (Fig. 6D, 1.7) und Basel (Fig. 7 B) teilweise vielleicht Bestandteile ehemaliger Paare zu 5 bis 2 Unzen, dürfen jedenfalls nicht unbesehen mit den jüngeren, oft unverzierten Stücken des 6. Jahrhunderts zusammengebracht werden.

\footnotetext{
$(90,2 \mathrm{~g}+88,5 \mathrm{~g}) \cdot-2$ Grab $447(72,0 \mathrm{~g}+67,6 \mathrm{~g}) .-3$ Grab $853(33,1 \mathrm{~g}+31,6 \mathrm{~g}) .-4$ Grab 146 $(31,4 \mathrm{~g}+30,7 \mathrm{~g})$. - 5 Grab $607(26,5+26,1 \mathrm{~g})$. - 6 Grab $934(25,8 \mathrm{~g}+25,4 \mathrm{~g}) .-7$ Grab 618 $(25,75 \mathrm{~g}+24,6 \mathrm{~g}) \cdot-8$ Grab $105(24,8 \mathrm{~g}+24,8 \mathrm{~g}) \cdot-9$ Grab $256(22,2 \mathrm{~g}+21,35 \mathrm{~g}) \cdot-10$ Grab 117 $(21,35 \mathrm{~g}+21,1 \mathrm{~g}) \cdot-11$ Grab $485(16,3 \mathrm{~g}+12,6 \mathrm{~g}) \cdot-12$ Grab $658(14,5 \mathrm{~g}+13,8 \mathrm{~g}) \cdot-13$ Grab 91 $(13,8 \mathrm{~g}+12,4 \mathrm{~g}) \cdot-14$ Grab $31(12,4 \mathrm{~g}+12,25 \mathrm{~g}) \cdot-15 \mathrm{Grab} 224(12,8 \mathrm{~g}+11,75 \mathrm{~g}) \cdot-16$ Grab 343 $(13,2 \mathrm{~g}+11,2 \mathrm{~g}) \cdot-17$ Grab $454(11,3 \mathrm{~g}+11,1 \mathrm{~g}) \cdot-18$ Grab $151(10,4 \mathrm{~g}+10,1 \mathrm{~g}) \cdot-19$ Grab 189 $(9,3 g+8,9 g) .-20$ Grab $1083(8,0 g+6,8 g) .-21$ Grab $521(7,3 g+6,8 g)$ - 22 Lesefund (ebd. Taf. $173,2.3)(6,7 g+6,3 g) .-23$ Grab $201(5,8 g+5,6 g)$.

${ }^{41}$ Vgl. die Zusammenstellung von Frauengräbern mit silbernem Armring bei UrsuL.A KocH, Alamannische Gräber der ersten Hälfte des 6. Jahrhunderts in Südbayern (Bayerische Vorgeschichtsblätter 34, 1969, S. $162-193)$ S. 187 ff. Tabelle 1.

${ }^{42}$ Die bei Косн (wie Anm. 41) Tabelle 1 aufgeführten Gräber mit (z. T. ungleichem) Paar silberner Armringe gehören durchweg noch ins 5. Jahrhundert und in die Zeit um 500.
} 
Bei den Basler Halsringen fallen die stark unterschiedlichen Gewichte von fast 5, 3 und 2 Unzen neben solchen zu $1 / 2$ bis $1 / 3$ (?) Unze auf (Fig. 7 C). Verwandte und auch etwa zeitgenössische Halsringe aus Heilbronn-Böckingen (175 g), Mahlberg, Ortenaukreis $(132,1 \mathrm{~g})$, und Alcagnano $(2 \times \text { : noch } 143,5 \mathrm{~g} \text { und } 86,5 \mathrm{~g})^{43}$ wogen $61 / 2$ und 5 Unzen, die beschädigten Exemplare aus Alcagnano einst vielleicht $51 / 2$ und $31 / 2$ Unzen.

Wenn auf dem Boden des alten Imperium Romanum entstandene silberne Bügelfibeln (s. o.) oder Gürtelschnallen ${ }^{44}$ der ostgotischen Frauentracht genauso wie spätantikes und byzantinisches Silbergeschirr und -gerät gewichtsmäßig den Normen des seit etlichen Jahrhunderten üblichen Gewichtssystems angepaßt sind, wird dies vielleicht nicht überraschen ${ }^{45}$. Nicht jedermann dürfte hingegen erwartet haben, daß nicht nur das skandinavische Gold, sondern auch das in der alten Germania libera und in den einstigen Grenzprovinzen des Römerreiches zu germanischem Frauenschmuck verwendete Silber nicht nach Augenmaß und nach der Menge des dem Silberschmied gerade übergebenen Altsilbers (und gemünzten Silbers) verarbeitet wurde. Selbst wenn, wie bei römischem Schmuck (s. o.), das einzeln oder paarweise angefertigte Objekt nach Fertigstellung gemäß dem Gewicht des dafür verwendeten Silbers bezahlt worden sein dürfte, waren doch bestimmte Gewichtskategorien (und ,Preisklassen') vorhanden, nach denen Besteller und Hersteller sich richteten ${ }^{46}$. Ob dabei das römische oder ein ihm entsprechendes und angepaßtes einheimisches System mit eigenen Bezeichnungen üblich war, ist im Grunde genommen eine zweitrangige Frage.

Wenn einzelne Schmucksachen in ihrem Gewicht nicht zum unzialen Gewichtssystem passen (Fig. 6-8), kann dies verschiedene Gründe haben und müßte einzeln geprüft werden: Außer Abnutzung mögen Bestandteile aus anderem Metall oder Steinauflagen, aber auch mangelnde Qualität die Ursache sein oder eben eine Anfertigung ohne Rücksicht auf Gewichtskategorien, die sicher nicht völlig ausgeschlossen werden darf. Ob dabei Zeit und Landschaft eine Rolle spielen, kann später vielleicht einmal entschieden werden.

Gerne wüßten wir auch, ob der Auftraggeber oder Käufer beim Silberschmied unter einer Anzahl von Modellen (mit bestimmtem Gewicht und Preis) wählen konnte. In Paris jedenfalls kann im Jahre 583 Leudastes, Graf von Tours, sich verschiedene fertige Schmuckstücke (diversa ornamenta) ansehen und überlegen, was

43 Heilbronn-Böckingen: Fundberichte aus Schwaben NF 12, 1952, S. 101 f. Taf. 22,1.3 (175 g). Mahlberg Grab von 1974: Fundberichte aus Baden-Württemberg 8, 1983, S. 407 Taf. 226 A,3 $(132,10 \mathrm{~g})$. - Alcagnano: Bierbrauer (wie Anm. 37, 1974) S. 561 Abb. 2,1 (143,5 g, leicht fragmentiert) Taf. 38,1 ( $86,5 \mathrm{~g}$, leicht fragmentiert).

44 Vgl. etwa vier ostgotische Gürtelschnallen des späteren 5. und des 6. Jahrhunderts aus Italien mit Gewichten von $135 \mathrm{~g}$ (=98,9\% von 5 Unzen), $150 \mathrm{~g}$ (=99,9\% von 51/2 Unzen), $158,5 \mathrm{~g}$ (=96,8\% von 6 Unzen?; leicht fragmentiert) und 186,3 g (=97,5\% von 7 Unzen): Bierbrauer (wie Anm. 37, 1975) S. $258-260,319$ f., 347 Taf. 4,1.2; 41; 51,3. - Kleine Steineinlagen auf den vier Schnallen dürften die an allen Exemplaren feststellbaren Abnutzungen gewichtsmäßig wettmachen.

45 Vgl. Martin (wie Anm. 7) und zuletzt Catherine M. Johns - Trmothy W. Potter, The Canterbury Late Roman Treasure (The Antiquaries Journal 65, 1985, S. 312-352) S. $334 \mathrm{f}$.

46 Auch neuzeitlicher nordafrikanischer Armringschmuck aus Silber existiert(e) in verschiedenen, vom Hersteller durch eine eingestempelte Ziffer markierten Gewichtskategorien. 
er für sein Geld, von dem er reichlich bei sich trägt, kaufen soll ${ }^{47}$. Zumindest in größeren Orten konnte man also fertigen Schmuck kaufen.

Anders als noch vor zwei Jahrzehnten stammen heute auch die zahlreicher gewordenen Belege für Fibelproduktion (Modelle und Gußformen für Bügelfibeln) größtenteils nicht mehr aus Goldschmiedegräbern ländlicher Siedlungen, sondern aus größeren, zentralen Plätzen, wie z. B. vom Runden Berg bei Urach, aus der Handwerkersiedlung Huy an der Maas (Prov. Liège) und vom Handelsplatz Helgö westlich von Stockholm ${ }^{48}$. Man wird demnach eher oder doch häufiger mit standortgebundenen Handwerkern und damit vielleicht auch zentralen Verkaufsplätzen mit einem Vorrat an Modellen und vereinzelt auch fertigen Schmuckstücken rechnen dürfen.

Ein weiteres Problem betrifft das beim Nachschneiden der Fibelgüsse abgehobene Silber. Wurde diese Silbermenge dort, wo der Auftraggeber das Edelmetall geliefert hatte, durch Wägen festgestellt und verrechnet ${ }^{49}$ ? Zumindest bei Silber, dessen Wert höchstens $1 / 10$ bis $1 / 15$ des Goldes betrug, scheint eine Toleranz von vielleicht $2-3 \%$ oder etwas mehr denkbar.

\section{SCHLUSS}

In der Germania libera, zu der auch Skandinavien gerechnet wird, war spätestens seit der späten Kaiserzeit und während des frühen Mittelalters, wie die oben zusammengetragenen Gewichte von Gold- und Silberobjekten, aber auch Gewichtssteine belegen, ein unziales Gewichtssystem üblich, das dem antiken römisch-byzantinischen vollkommen entsprochen haben muß. Diese enge Bindung oder Übereinstimmung mit den Gewichtsnormen der alten Welt wird seit einigen Jahren auch von skandinavischen Archäologen hervorgehoben ${ }^{50}$. Edelmetall wurde

47 Gregorii episcopi Turonensis libri historiarum X, hg. von BRuno KrusCh - Wilhelm Levison (MGH SS rer. Merov. 1,1) Hannover 21951, VI c. 32, S. 303. Vgl. Dietrich Claude, Beiträge zur Geschichte der frühmittelalterlichen Königsschätze (Early Medieval Studies 7. Antikvariskt arkiv 54, 1973, S. 5-24) S. 12.

$48 \mathrm{Zu}$ den genannten Fundplätzen vgl. z. B. Charles Bonnet - Max Martin, Bleimodell einer angelsächsischen Fibel aus Saint-Pierre in Genf (Archäologie der Schweiz 5, 1982, S. 210-224) S. 218 f. Abb. 16-18. - Mehrere verschiedene Fälle der Produktion und Verbreitung führt JoAchrm WERnER, Zur Verbreitung frühgeschichtlicher Metallarbeiten (Early Medieval Studies 1. Antikvariskt arkiv 38, 1970, S. 65-81) vor.

49 Es darf hier auf die zwei verschiedenen Gewichtsangaben einer spätrömischen Silberplatte zu 15 Pfund von Kaiseraugst hingewiesen werden, deren Differenz die beim Herausschneiden der figürlichen Darstellungen angefallene Silbermenge festhalten dürfte: MARTIN (wie Anm. 7) S. 383.

50 EgIL BAKKA, Two aurar of gold. Contributions to the Weight History of the Migration Period (The Antiquaries Journal 58, 1978, S. 279-298) S. 279 ff., 292 ff.; S. 296 wird angenommen, daß die frühen Schlangenkopfarmringe (vgl. unsere Fig. 3) nicht in das auf dem römischen Gewichtssystem fußende einheimische System einzuordnen seien, dessen Rezeption demnach wohl erst nach der konstantinischen Münzreform erfolgt sei; Ders., A Set of Weights from Late Roman or Early Migration Times Found at Bråten in Ringerike, Eastern Norway (Frühmittelalterliche Studien 15, 1981, S. 294-315) S. 294, 305 (mit leicht differierenden Gewichtsstandards, die u. a. bis zu $7 \%$ über und 3\% unter dem römischen Standard liegen sollen); Elizabeth Munksgaard, Weight adjusted rings from the Germanic Iron Age and the Viking period (Aarbøger for nordisk oldkyndighed og historie 1978 [1980]) S. 150-154; Dies., Guldringe fra Fyn og Himmerland (P. V. Glob [Red.], 
nicht nach Münzen gezählt, sondern in Unzen und Teilen der Unze gewogen, verhandelt und zu Schmuck verarbeitet. Dies gilt nicht nur für Gold, sondern auch für Silber, wenngleich jenes wegen seines mehrfach höheren Wertes stets exakter gewogen und verarbeitet wurde.

Ein guter Teil des Goldes und auch des Silbers in germanischer Hand mag auf römisches Gold- und Silbergeld zurückgehen, das durch Handel oder Beutezüge und Tributzahlungen erworben wurde. Dies zeigen die vielen Funde von Solidi des 4. und 5. Jahrhunderts ${ }^{51}$, aber auch die nachweislich bis ins 6 . Jahrhundert vorhandenen guten römischen Denare des späteren 1. und 2. Jahrhunderts, die thesauriert wurden ${ }^{52}$, aber beispielsweise genausogut wie ostgotische oder byzantinische Silbermünzen als Oboli verwendet werden konnten ${ }^{53}$. Auch bei den Solidi wird man sich des Vorteils der Garantie des Feingehalts dank spätrömisch-byzantinischer Prägung bewußt gewesen sein.

Trotz der Bedeutung, die diesem Edelmetallzufluß in gemünzter Form zweifellos zugekommen sein muß, darf der Zustrom von Gold und Silber aus Schmuck, Geschirr und Gerät nicht unterschätzt werden. Überhaupt ist festzuhalten, daß Edelmetall ja seit vorrömischer Zeit vorhanden war, verhandelt und verarbeitet wurde. Dies erforderte auch in der Germania libera Wägemöglichkeiten und Gewichtseinheiten, bevor Gold- und Silbergeld auftauchte oder Hauptbestandteil einer Geldwirtschaft wurde.

Die Gewichte goldener (und silberner) Schmuckstücke und Insignien sind darum unabhängig vom Gewicht vorhandener Edelmetallmünzen zu betrachten;

Danefae, Kopenhagen 1980) S. 24; UlF ERIK HaGBerg, Ein Schatzfund der Völkerwanderungszeit: Djurgårdsäng bei Skara, Västergotland, Schweden (Studien zur Sachsenforschung 4, 1983, S. 79-92).

51 Herschend (wie Anm. 27) S. 33 ff. (mit Lit.); Ola Kyhlberg, Vikt och Värde (Stockholm Studies in Archaeology 1) Stockholm 1980, S. 12, 33 ff.; JAN ILUK, The export of gold from the Roman Empire to barbarian countries from the 4th to the 6th centuries (Münstersche Beiträge zur antiken Handelsgeschichte 4,1, Ostfildern 1985, S. 79-102) S. 97-99 Tabelle 6.

52 So etwa dürften die an die 200 römischen Denare des 2. Jahrhunderts, die im Grab des Königs Childerich (†482) mitgegeben waren (vgl. zuletzt Kurt BöHner, Childerich von Tournai [Reallexikon der Germanischen Altertumskunde 4, 21981, S. 441-460] S. 454, und JoACHIM Werner, Childerich, Geschichte und Archäologie [Antike Welt 14, 1983, S. 28-35]), nicht aus einem kurz vor 482 entdeckten Denarhort stammen (so Jean Lafaurie, Archéologie médiévale 1, 1971, S. 175), sondern wie die Goldmünzen dem königlichen Thesaurus entnommen worden sein. Zu den Thesauri vgl. Claude (wie Anm. 47) S. 19 ff. (hier Denare nicht genannt). - Vgl. auch Joachim Werner, Münzdatierte austrasische Grabfunde, Berlin-Leipzig 1935, S. 6 Anm. 4; ferner unten S. 235.

$53 \mathrm{Zu}$ Denaren als Oboli in Gräbern des späteren 4. und der 1. Hälfte des 5. Jahrhunderts vgl. Horst W. BöнмE, Germanische Grabfunde des 4. bis 5. Jahrhunderts zwischen unterer Elbe und Loire (Münchner Beiträge zur Vor- und Frühgeschichte 19) München 1974, S. $149 \mathrm{ff}$. - Die Belege aus Gräbern der 2. Hälfte des 5. und des 6. Jahrhunderts wurden bisher nicht zusammengestellt. Einige Beispiele: Mézières (Dép. Ardennes) Grab 89: Patrick Perin (Revue historique ardennaise 10, 1975) S. 15 Fig. 13,1 (Denar 2. Jahrh. n. Chr.). - Merlemont Grab 16: Yves Wautelet, La nécropole franque de Merlemont (Archaeologia Belgica 100, Bruxelles 1967) S. 28 Abb. 19,2 (Denar 1. Jahrh. v. Chr.). - Flonheim Grab 9: Hermann Ament, Fränkische Adelsgräber von Flonheim (Germanische Denkmäler der Völkerwanderungszeit Ser. B, 5) Berlin 1970, S. 96 (Republikdenar). Leihgestern Grab 4: HeINRICH KLENK (Mitteilungen des Oberhessischen Geschichtsvereins NF 48, 1964) S. 27 Taf. 7, 5, 4 (Denar 2. Jahrh. n. Chr.). 
daß auch diese Münzen, vorab der Solidus als Sechstel der Unze ${ }^{54}$, ins allgemeine Gewichtssystem eingebunden waren, schafft gewissermaßen zusätzliche Verbindungen. Tributzahlungen des Weströmischen und Oströmischen Reiches an die Hunnen oder Germanen wurden in Goldpfunden (zu je 72 Solidi) festgelegt und vom Empfänger zweifellos auch dementsprechend kontrolliert; erst seit dem späteren 6 . Jahrhundert kommen Angaben auf, die eine runde Zahl von Münzen nennen (vgl. Anhang 2).

Auch Feinwaagen müssen primär zum Wägen kostbarer Güter (Edelmetall, evtl. auch Buntmetall, Bernstein und Gewürze) benutzt worden sein; dazu gehörten unter anderem auch Münzen aus Gold und Silber. Nach der Größe der erhaltenen Gewichte wurden die im merowingischen Reihengräberkreis und im angelsächsischen Bereich üblichen Feinwaagen ${ }^{55}$ für Wägungen bis zu einem Gewicht von etwa 1-2 Unzen verwendet. Bei den mit den Waagen gefundenen Gewichten sind zunächst Bronzegewichte mediterraner Herkunft zu nennen, die im Grab von Lutlommel (Fig. 9) 1, 1/2, 1/3 und 1/6 Unze schwer sind, in Singen und Schwabsburg je 1 Unze $^{56}$. Zusammen mit 'einheimischen' Gewichtssteinen machen sie deutlich, daß „das römisch-byzantinische Unzialsystem überall im Merowingerreich Anwendung fand “57. Unter diesen einheimischen Gewichten aus Bronze und Blei ${ }^{58}$, die leider bisher noch nicht ausführlich bearbeitet wurden, ist eine von J. Werner

54 Vor dem 4. Jahrhundert kam auf eine Unze nur selten eine runde Zahl von Aurei (oder Denaren), z. B. einige Jahre nach 193, als der Aureus $1 / 48$ des Pfundes wog, und ab 286, als 60 Aurei ein Pfund, d.h. 5 eine Unze schwer waren.

55 Werner (wie Anm. 31); Ders., Fernhandel und Naturalwirtschaft im östlichen Merowingerreich nach archäologischen und numismatischen Zeugnissen (42. Bericht der Römisch-Germanischen Kommission 1961, S. 307-346) S. 327-329, 345 f; ein Nachtrag mit 15 Feinwaagen vorab aus Gräbern Ostfrankreichs bei Henri Gaillard de Semainville, Le cimetière mérovingien de SaintClément-sur-Guye (Revue de la Physiophile de Montceau-les-Mines 1979, Nr. 91, S. 21 - 52) S. 45. Zur Interpretation des Verbreitungsbildes der Feinwaagen vgl. Martin (wie Anm. 37) S. 68; anders zu den Belegen östlich des Rheins Rainer Christrein, Die Alamannen, Stuttgart 1978, S. 111. Die angelsächsischen Belege jetzt bei Christopher Scull, A Sixth-Century Grave Containing a Balance and Weights from Watchfield, Oxfordshire, England (Germania 64, 1986, S. 105-138) S. 127 Abb. 14.

56 Lutlommel (Prov. Limburg): Jacques Breuer - JeAnnine Alenus-Lecerf, La boîte à poids

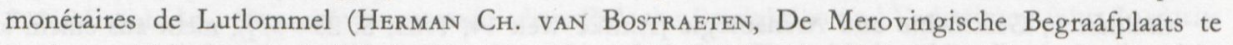
Lutlommel [Archaeologia Belgica 86] Bruxelles 1965) S. 103-116 Abb. 20.21 (heutiges Gewicht . der vier viereckigen Bronzegewichte: $26,12 \mathrm{~g}, 13,75 \mathrm{~g}, 8,35 \mathrm{~g}, 4,05 \mathrm{~g}$ ). - Singen Männergrab 75: Gerhard Fingerlin, Neue alamannische Grabfunde aus Singen a. H., Ldkrs. Konstanz (Badische Fundberichte 22, 1962, S. 119-132) S. 120 f. Taf. 39,9; 41,3 (viereckiges Bronzegewicht, noch 27,2 g schwer). - Schwabsburg bei Nierstein (aus Grab?): Gustav Behrens, Merowingische Gewichte und Waagen (Mainzer Zeitschrift 34, 1939, S. 17-22) S. 19 Abb. 3 (rundes Bronzegewicht, noch $25,35 \mathrm{~g}$ schwer). - Vgl. auch das viereckige byzantinische Bronzegewicht von noch 80,05 g (= 97,8\% von 3 Unzen) vom Runden Berg bei Urach: Rainer Christrein, Der Runde Berg bei Urach I (Abhandlungen der Heidelberger Akademie der Wissenschaften. Phil.-Hist. Klasse Jg. 1974, 1. Abhandlung) Heidelberg 1974, S. 27, 42 Taf. 10,9; 31,1.

57 Werner (wie Anm. 31) S. 17.

58 In einem Hortfund bei Holta in Rogaland (Werner [wie Anm. 31] S. 23 Taf. 2; Bakka [wie Anm. 50, 1978] S. 283 ff. Taf. 57b; Ders. [wie Anm. 50, 1981] S. 295) fanden sich nebst Ringgold und Brakteaten auch zwei Bleigewichte zu 53,47g (=98,0\% von 2 Unzen) und $18,83 \mathrm{~g}(=103,5 \%$ einer $2 / 3$ Unze). 

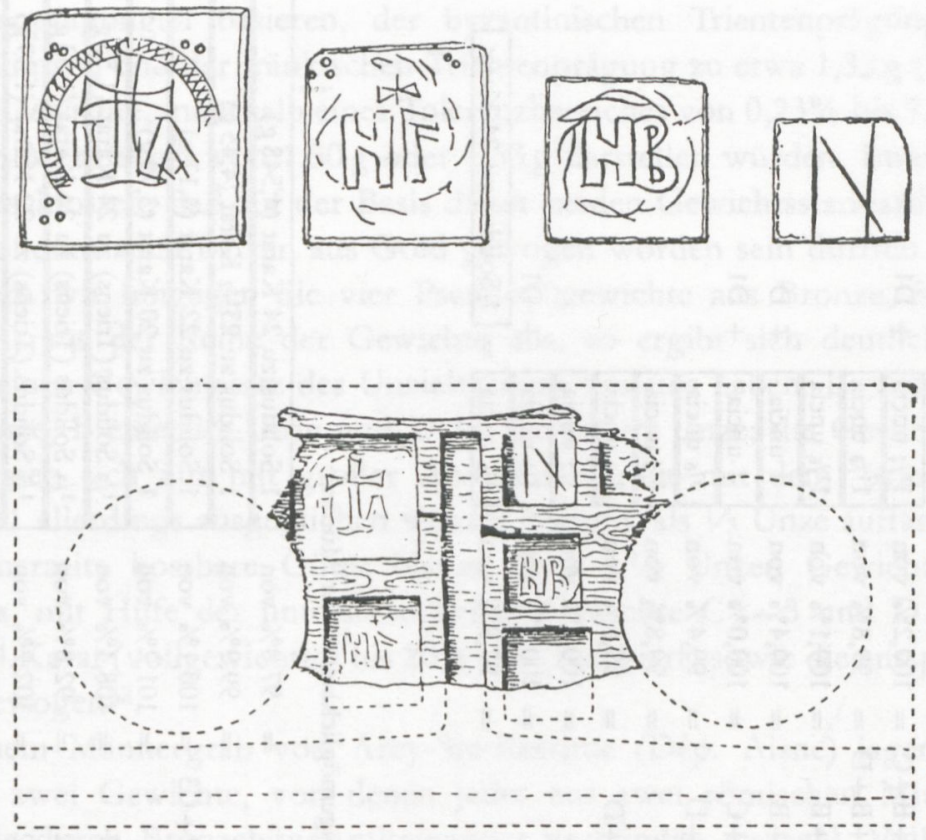

Fig. 9 Lutlommel (Prov. Limburg): Vier byzantinische bzw. mediterrane Bronzegewichte zu 1, 1/2, $1 / 3$ und $1 / 6$ Unze. 1:1. - Rekonstruktion des zugehörigen, nur noch bruchstückhaft erhaltenen Feinwaagefutterals aus Erikaholz, mit Resten von noch sechs Aussparungen für Gewichte. 1:2. Vgl. Anm. 56.

bereits kurz erwähnte Gruppe zu nennen, die vor allem aus Grabfunden Nordfrankreichs und Englands bekannt ist: Hier wurden zusammen mit Feinwaagen römische Bronzemünzen, oft ganze 'Sätze' zu 4, 9, 14 bis zu 20 Münzen ${ }^{59}$ gefunden, die wegen sekundärer Bearbeitung oder Verbindungsgliedern zwischen je 2 (oder mehr) Münzen nicht als Altmetall, sondern als Gewichtssteine anzusprechen sind.

Ein Neufund von 1983 aus einem bald nach der Mitte des 6. Jahrhunderts angelegten Männergrab bei Watchfield (Oxfordshire), in dem eine gleicharmige Feinwaage in Lederetui mit insgesamt 12 Gewichten exakt untersucht werden konnte, läßt sehr schön erkennen, warum römische Münzen wiederverwendet wurden und welches Gewichtssystem üblich war (Fig. 10) ${ }^{60}$ : Zur Waage von Watchfield gehörten ein byzantinisches Gewicht (D 1) - offenbar eine einheimische Imitation - zu 8 Siliquae $(=8$ Karat $=1 / 3$ Solidus), 1 keltische Potinmünze (C 3$)$, 6 römische Bronzemünzen des 2 . und 4. Jahrhunderts (A; B; C 1.2; D 2.3) sowie 4 münzähnliche Gewichte aus Bronze (E), Kupfer (F) und Blei $(\mathrm{G}, \mathrm{H})^{61}$. In der Vorlage des Fundes durch Chr. Scull wird die Meinung vertreten, die zwölf Gewichte würden sehr eng auf den Gewichtsstandards zweier zeitgenössischer

59 Werner (wie Anm. 31) S. 20 f., 32 ff., 37 f.; Scull (wie Anm. 55) S. 128; Vera I. Evison, The Dover Ring-sword and Other Sword-rings and Beads (Archaeologia 101, 1967, S. 63-118) S. 86 Abb. 4 g-i; Kyhlberg (wie Anm. 51) S. 164 ff. (Gilton Grab 66).

60 Scull (wie Anm. 55) S. 114 ff. Abb. 9 Tabelle 1.

61 Wozu die vier Pseudo(?)gewichte E-H verwendet wurden, ist mir nicht klar und wurde hier nicht weiter verfolgt. 

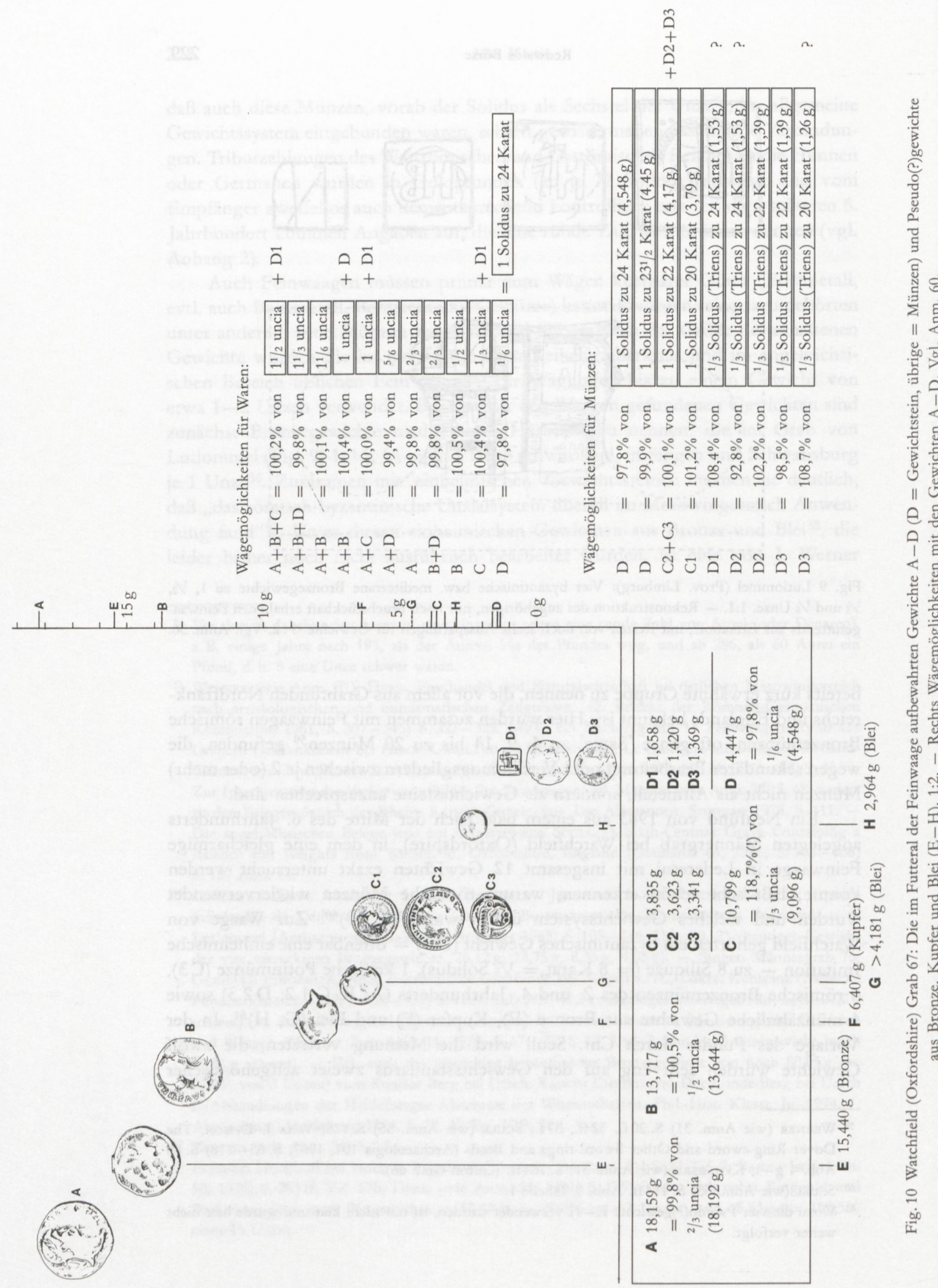
Goldmünzenprägungen basieren, der byzantinischen Trientenprägung zu etwa $1,52 \mathrm{~g}$ (8 Siliquae) und der fränkischen Trientenprägung zu etwa 1,33 g (7 Siliquae), da fast alle Gewichte, innerhalb eines Toleranzbereiches von 0,23\% bis 7,33\% (bzw. $8,53 \%$ ), ein Mehrfaches von 1,30 g oder 1,53 g darstellen würden. Immerhin wird nicht ausgeschlossen, daß auf der Basis dieser beiden Gewichtsstandards nicht nur Münzen, sondern auch Barren aus Gold gewogen worden sein dürften.

Sondern wir hingegen die vier Pseudo(?)gewichte aus Bronze, Kupfer und Blei $(\mathrm{E}-\mathrm{H})$ aus der Reihe der Gewichte aus, so ergibt sich deutlich, daß wir wiederum einen Gewichtssatz des Unzialsystems vor uns haben: Es entsprechen A einer $2 / 3$ Unze, B einer $1 / 2$ Unze und D $1-3$ einer $1 / 6$ Unze; die Gewichte C $1-3$ dagegen lassen sich nur mit großer Abweichung, die mit dem 'byzantinischen' Gewicht D 1 allerdings ausgeglichen werden konnte, als $1 / 3$ Unze auffassen. Sicher wurden einerseits kostbare Güter bis zu etwa 11/2 Unzen Gewicht (40,93 g), andererseits, mit Hilfe der unterschiedlichen Gewichte C1-3 und D 1-3, auch Solidi zu 24 Karat (vollgewichtig) bis 20 Karat (reduziert) sowie die entsprechenden Trienten gewogen ${ }^{62}$.

In einem Männergrab von Arcy-Ste-Restitue (Dép. Aisne) lagen bei einer Feinwaage zwei Gewichte, von denen jedes aus zwei römischen Mittelbronzen bestand, die durch Bronzebügel miteinander verbunden waren ${ }^{63}$. Vollausgeprägt wogen, bis ins frühe 3. Jahrhundert, der Sesterz (4 Asse) eine Unze, der Dupondius (2 Asse) eine halbe Unze ${ }^{64}$. Dies erklärt, warum diese schweren Münzen später teils unverändert, teils kombiniert oder abgewandelt im Rahmen des weitergeführten 'römisch-byzantinischen Unzialsystems' als Gewichte verwendet wurden; die leichteren spätrömischen Kupfermünzen entsprachen dagegen - eher schlecht als recht - kleineren Gewichtseinheiten.

62 Zwei zylindrische Bronzestäbchen gleicher Form (Länge $29 \mathrm{~mm}$, Durchmesser 6,4 mm; Gewicht $7,367 \mathrm{~g}$ und 7,362 g) am Gehänge eines um 600 angelegten Frauengrabes im Gräberfeld von Liebenau scheinen mir hingegen weniger zum Wägen zeitgenössischer Goldmünzen, von je 6 reduzierten Trienten zu 1,26 g (bzw. je 2 reduzierten Solidi zu 3,79 g), gedient zu haben (Friedrich B. Naber, Ein Grab mit zwei bronzenen Münzgewichten aus dem sächsischen Gräberfeld Liebenau, Kr. Nienburg/Weser [Studien zur Sachsenforschung 2, 1980, S. 289-300]), sondern viel eher (in nicht mehr ursprünglicher Funktion am Gehänge angebrachte) kaiserzeitliche Gewichte zu sein, die einst zum Wägen von Aurei zu 1/45 Pfund $(7,28 \mathrm{~g}$ ) benutzt wurden, wie sie im späten 1. und im 2. Jahrhundert $\mathrm{n}$. Chr. üblich waren. Vgl. jetzt ein gleiches silbernes Stäbchen zu $16,2 \mathrm{~g}(=98,9 \%$ von $16,37 \mathrm{~g}=2$ Aurei zu 1/40 Pfund) aus einem römischen Militärlager bei Kalkar: Rolf RotrtLäNDER, Zum Abwiegen von Metallen (Das Rheinische Landesmuseum. Berichte aus der Arbeit des Museums 1984, Heft 5, S. 79 f.).

63 Werner (wie Anm. 31) S. 32; Jules Prlloy, Une balance du $7^{e}$ siècle découverte dans le cimetière de Montescourt (Dép. Aisne) (Bulletin archéologique 1898, S. 107-113) S. 109: „Chaque peson ... est composé de deux monnaies que nous avons reconnu être un moyen bronze de Vespasian et un moyen bronze de Marc-Aurèle. Elles sont seriées comme avec un coin par une aiguillette de ceinturon, maintenues en groupe par une petite patte en bronze fort élégante.“

${ }^{64}$ Der in Watchfield gefundene „corroded orichalchum dupondius of Hadrian (A.D. 117-138)“ (Scull [wie Anm. 55] S. 115, Abb. 9,22 = hier Fig. 10 A) scheint mir nach seinem Gewicht $(18,159 \mathrm{~g})$ und der fehlenden Strahlenkrone ein zu einem $2 / 3$ Unzen-Gewicht zurechtgemachter Sesterz von ursprünglich 1 Unze Gewicht zu sein. Vgl. den zu einem Gewicht umgestalteten Sesterz in Grab C von Dover: Evison (wie Anm. 59) Abb. $4 \mathrm{i}$. 
Wiederum zeigt sich, daß auch im England des 6. Jahrhunderts kostbare Güter nach dem unzialen Gewichtssystem gewogen wurden. Wenige Jahrzehnte später belegt Redwalds Börse mit ihren 21/4 Unzen Gold, daß dieses Metall - gemünzt und ungemünzt - nach Unzen oder Teilen der Unze gewogen, verhandelt, aber auch verarbeitet und thesauriert wurde.

\section{ANHANG 1: DIE GEWICHTE EINIGER GOLDOBJEKTE AUS DEN GRÄBERN EINER LANGOBARDISCHEN ADELSFAMILIE BEI CIVIDALE}

In der nachstehenden Tabelle 6 folgen die Gewichte einiger Goldobjekte aus einer kleinen Gruppe von Gräbern bei der Kirche S. Stefano vor den Toren von Cividale, in denen bald nach 568 Angehörige einer langobardischen Adelsfamilie oder -sippe beigesetzt wurden. Außer einem am reichsten ausgestatteten Männergrab fanden sich die Bestattungen von fünf Knaben und eines Mädchens, dem am wenigsten Gold, dafür zwei kostbare Behälter, ein kugeliger Glasbecher mit Fiedermuster und ein verziertes Kästchen aus Bein, mitgegeben worden waren ${ }^{65}$.

Das im Männergrab 1 und Knabengrab 12 gefundene Gürtelzubehör aus Gold ist leider unvollständig, da die Schnallenbügel, wohl die massivsten Bestandteile, offenbar nicht mitgegeben, jedenfalls nicht mehr vorhanden waren. Ob nicht nur einzelne Teile, wie das Schnallenbeschläg in Grab 1, sondern der ganze Gürtelbesatz jeweils nach festen Gewichten hergestellt war, läßt sich nicht mehr sagen.

$\mathrm{Ob}$ Goldlahn von insgesamt 18,4 g bzw. $12 \mathrm{~g}$ in den Gräbern 11 und 2 auf Tücher oder auf Kleider hinweisen, an denen einst Gold im Gewicht einer 2/3 Unze $(18,19 \mathrm{~g})$ bzw. $1 / 2$ Unze $(13,64 \mathrm{~g})$ verarbeitet war, müßte anhand weiterer Gewichtsangaben zu Goldlahn geprüft werden.

Von den in allen sieben Gräbern zum Vorschein gekommenen Goldblattkreuzen ist das des in Grab 1 bestatteten Mannes 13,7 g schwer, wogegen die der sechs Kinder zwischen 5,2 und 3,7 g (Mittel 4,3 g) wiegen. Das Kreuz aus Grab 1 ist offensichtlich $1 / 2$ Unze, die Kreuze der Kinder sind - allerdings mit kräftigen Abweichungen - jeweils $1 / 6$ Unze schwer. Je kleiner und leichter Objekte wie z. B. eben Goldblattkreuze oder Fingerringe sind, umso schwieriger ist der Nachweis fester oder angestrebter Gewichtseinheiten. Angesichts der doch deutlichen Gewichtsunterschiede ist aber zu fragen, ob hier nicht - bei allen oder dann nur bei den sechs Kinderkreuzen - jeweils Goldmünzen, entweder Solidi oder Trienten, verarbeitet wurden. Metallanalysen der Kreuze und von Goldmünzen, allerdings ausnahmslos von Prägungen, die im letzten Drittel des 6. Jahrhunderts in Oberitalien zum üblichen Geldumlauf gehörten ${ }^{66}$, könnten wohl klären, ob diese allein aus den unregelmäßigen Gewichten der Kreuze abgeleitete Hypothese zutrifft ${ }^{67}$. Da

65 Carlo Mutinelli, Das langobardische Gräberfeld von S. Stefano in Pertica in Cividale (Jahrbuch Römisch-Germanisches Zentralmuseum Mainz 8, 1961, S. 139-156); OTTO von Hessen, Langobardische Goldblattkreuze aus Italien (Die Goldblattkreuze des frühen Mittelalters, hg. von WolfGANG HÜBENER, Bühl/Baden 1975) S. $114 \mathrm{f}$.

66 So dürfte etwa auch in Italien der Silbergehalt in Goldmünzen seit dem späteren 6. Jahrhundert sehr starken Veränderungen unterworfen gewesen sein.

67 Bisher liegen erst wenige Analysen vor, die noch keine Schlüsse erlauben, vgl. Axel HartmanN Rotraut Wolf, Vergleichende Spektralanalysen an einigen frühmittelalterlichen Goldfunden und Goldblattkreuzen (Die Goldblattkreuze des frühen Mittelalters [wie Anm. 65] S. 23-30). 
TABELLE 6:

GEWICHTE DER IM FRIEDHOF VON CIVIDALE - S. STEFANO IN PERTICA

GEFUNDENEN GOLDBLATTKREUZE,

GOLDLAHNRESTE UND GÜRTELTEILE AUS GOLD

(vgl. Anm. 65)

Grab 1 (Mann):

Dreiteilige Gürtelgarnitur:

Schnalle, Beschläg

Schnalle, Bügel und Dorn

(nicht beigegeben?)

Gegenschläg

Rückenbeschläg

Große Riemenzunge

Kleine Riemenzunge

Goldblattkreuz

\section{Grab 12 (Knabe):}

Gürtel mit beschlägloser Schnalle:

Schilddornschnalle, Dorn

Schilddornschnalle, Bügel (nicht beigegeben?)

6 Gürtelhaften zusammen

Rückenbeschläg

Kleine Riemenzunge

Goldblattkreuz

Grab 11 (Knabe):

Goldlahnteile

Goldblattkreuz

$18,4 \mathrm{~g}=101,2 \%$ von $2 / 3$ uncia $(18,19 \mathrm{~g})$

$5,2 \mathrm{~g}=$ a) $114,3 \%$ von $1 / 6$ uncia $(4,548 \mathrm{~g})(?)$, eher aber

= b) $93,5 \%$ von 4 reduzierten Trienten $=11 / 3$ Solidus zu 22 Karat $(4,17 \mathrm{~g}+1,39 \mathrm{~g})$

Grab 2 (Knabe):

Goldlahnteile

Goldblattkreuz

$12 \mathrm{~g}=88,0 \%$ von $1 / 2$ uncia $(13,644 \mathrm{~g})$ ?

$4,4 \mathrm{~g}=96,7 \%$ von $1 / 6$ uncia $(4,548 \mathrm{~g})=1$ Solidus $\mathrm{zu}$ 24 Karat $(4,548 \mathrm{~g})$

Grab 4 (Knabe):

Goldblattkreuz

$4,5 \mathrm{~g}=98,9 \%$ von $1 / 6$ uncia $(4,548 \mathrm{~g})=1$ Solidus $\mathrm{zu}$ 24 Karat $(4,548 \mathrm{~g})$

Grab 13 (Knabe):

Goldblattkreuz

$4,2 \mathrm{~g}=$ a) $92,3 \%$ von $1 / 6$ uncia $(4,548 \mathrm{~g})(?)$, eher aber

= b) $100,7 \%$ eines reduzierten Solidus zu 22 Karat $(4,17 \mathrm{~g})$

Grab 3 (Mädchen):

Goldblattkreuz

$4 \mathrm{~g}=$ a) $88,0 \%$ von $1 / 6$ uncia $(4,548 \mathrm{~g})(?)$, eher aber

= b) $95,9 \%$ eines reduzierten Solidus zu 22 Karat $(4,17 \mathrm{~g})$ 
die Langobarden weder in Pannonien noch in Italien die Sitte des Münzobolus kannten ${ }^{68}$, wird man nicht schließen dürfen, daß das Goldblattkreuz bei ihnen den Grabobolus ersetzt habe. Immerhin fällt für das alamannisch-bajuwarische Gebiet nördlich der Alpen auf, daß der hier ebenfalls rezipierte Totenbrauch des Goldblattkreuzes nie mit dem Münzobolus vergesellschaftet ist, obwohl beide Bräuche ganz oder vorwiegend auf die oberste Gesellschaftsschicht konzentriert sind ${ }^{69}$.

\section{ANHANG 2: GOLDZAHLUNGEN UND SOLIDIHORTE}

Vor kurzem hat J. Iluk gezeigt, daß die Goldzahlungen, die das Weströmische und insbesondere das Oströmische Reich als jährliche Tribute, einmalige Zahlungen, Geschenke usw. an Germanen, Hunnen und Perser leisteten, im 5. und 6. Jahrhundert jeweils nicht in einer bestimmten Zahl von Goldmünzen (Solidi), sondern in Pfundgewichten festgesetzt und notiert wurden ${ }^{70}$. In der Regel wurden diese Subsidien von den betreffenden Völkern, die als Gegenleistung den Schutz der Reichsgrenzen übernahmen, am kaiserlichen Hof abgeholt. Kleinste Rechnungseinheit war bei diesen staatlichen Zahlungen fast immer das Kentenarion, d. h. Hundert Pfund Gold $(32,745 \mathrm{~kg})$, die in einem zugebundenen (und zweifellos versiegelten) Sack aufbewahrt waren ${ }^{71}$.

Bereits im Codex Theodosianus sind, wie hier ergänzend anzumerken ist, in Erlassen des späteren 4. und frühen 5. Jahrhunderts festgesetzte Mengen an Gold, die beispielsweise als Strafe zu entrichten waren, in Gewicht (beispielsweise 50, 30, 6 und 5 Pfund oder 6 Unzen, d.h. $1 / 2$ Pfund) angegeben. Die Gewichtsangaben der Goldzahlungen des 5. und 6. Jahrhunderts beruhen also auf älterer Übung.

Obwohl in den Quellen nicht Geldsummen, sondern Gewichte genannt sind, wurde auch nach 400 das Gold wohl zum allergrößten Teil in gemünzter Form, also in Solidi, ausbezahlt und kaum je auch in Barren oder Schmuckstücken, wie J. Iluk vermutet: Zum einen gehören die von ihm angeführten Barren dem 4 . Jahrhundert an und sind jüngere nicht bekannt ${ }^{72}$. Zum andern enthalten die Münzschätze des 5. und 6. Jahrhunderts nie Goldbarren, sondern nur Goldmünzen, stets Solidi, die bezeichnenderweise in großer Zahl auch als Einzelfunde aus dem Barbaricum bekannt sind ${ }^{73}$. Auch J. Iluks Meinung, die Höhe der Zahlungen sei durch Gewicht definiert worden, weil nur ein kleiner Teil der Goldmünzen 1/72 Pfund (normales Solidusgewicht) gewogen hätte und außer Solidusteilstücken eben

68 Joachim Werner, Die Langobarden in Pannonien (Abhandlungen Bayerische Akademie der Wissenschaften Phil.-Hist. Klasse NF 55) München 1962, S. 88.

$69 \mathrm{Vgl}$. den soziologischen Hintergrund der Goldblattkreuze und eine Liste der Vorkommen nördlich der Alpen bei Rainer Christrein (Die Goldblattkreuze des frühen Mittelalters [wie Anm. 65]) S. 73 ff. Abb. 5 und S. 105 ff. Nrn. 1-51.

70 ILuk (wie Anm. 51).

71 Ebd. S. 84 f. - Zu beschrifteten Münzbeuteln vorab aus spätrömischer Zeit vgl. STEFAN KARwiESE, Münzdatierung „Aus dem Beutel“ (Jahreshefte des Österreichischen Archäologischen Instituts in Wien 50, 1972-1975, S. 281-295).

72 Zu den Goldbarren vgl. jetzt Bernhard und Mechthild Overbeck (Chiron 15, 1985, S. 199-210).

${ }^{73} \mathrm{Vgl}$. Anm. 51 und jetzt auch Ola Kyhlberg, Late Roman and Byzantine Solidi (Excavations at Helgö 10, hg. von Agneta Lundström - Helen Clarke, Stockholm 1986, S. 13-126). 
auch schwerere und leichtere Solidi im Umlauf gewesen seien, läßt sich nicht aufrechterhalten. Abgesehen davon, daß der byzantinische Staat dieses Gold wohl kaum dem Umlauf entnahm und vermutlich meist, wie der Hortfund von Szikáncs (s. u.) annehmen läßt, prägefrische Münzen lieferte, war nach Ausweis dieses und anderer Horte die Goldprägung im 5. Jahrhundert derart präzis und der Umlauf der Goldmünzen derart einheitlich, daß aus dieser Sicht die Zahlungen genausogut in Solidi hätten ausgedrückt werden können, wenn eben nicht die Gewichtsangabe üblich gewesen wäre; die von J. Iluk angesprochenen leichteren Solidi (zu 22, dann 20 Karat) wurden überdies erst ab 538 geschlagen ${ }^{74}$. Schließlich ist auch die Tatsache, daß Zahlungen überliefert seien, die nun doch, wenngleich „only very occasionally "75, in Solidi berechnet seien, kein Argument, in anderen Fällen Zahlungen in ungemünztem Gold zu vermuten, da die in dieser Weise überlieferten Zahlungen sich nicht über den ganzen von J. Iluk betrachteten Zeitraum verteilen, sondern auf die Zeit nach 550 konzentrieren (s. u.). Vielmehr scheint diese jüngere Formulierung geradezu zu bestätigen, daß schon vorher die Goldzahlungen in der Regel in Solidi erfolgten.

Dieses in Solidi ausgemünzte Gold stellte gewissermaßen eine Vielzahl gestempelter 'Kleinstbarren' dar. Ihr Feingehalt war dank staatlicher Prägung garantiert, eine Sicherheit, auf die man zweifellos nicht früher als nötig und wohl erst beim Einschmelzen und Verarbeiten verzichten wollte. Derselbe Grund ist m. E. auch hinter der langen Lebenszeit (nicht Umlaufzeit!) römischer Denare des späteren 1. und ganzen 2. Jahrhunderts zu suchen, die in der Germania libera und im frühen Frankenreich bis ins 4 . und 5., vereinzelt noch im 6. Jahrlrundert vorhanden waren: Diejenigen Bevölkerungskreise, die zu ihren Vermögenswerten auch Edelmetall zählten, werden diese aus gutem Silber hergestellten Denare erst bei Bedarf eingeschmolzen und sonst in geprägtem Zustand belassen haben. So sind die Denare in Horten des 4. Jahrhunderts und - als Teil des königlichen Thesaurus - im Grab des fränkischen Königs Childerich sowie schließlich - als Oboli - noch in Grabinventaren des 6 . Jahrhunderts zu erklären ${ }^{76}$.

Nach J. Iluks Berechnungen dürfte Byzanz allein im 5. Jahrhundert über 100’000 Pfund Gold, d. h. mehr als 7,2 Millionen Solidi für Tribute u. ä. aufgewendet haben. Da jedoch selbst diese eindrücklichen Summen, wie man schätzt, den jährlichen Staatshaushalt nur minim belasteten, wird auch die daraus resultierende Mehrbelastung der Münzprägestätten sich in Grenzen gehalten haben ${ }^{77}$.

Um zu prüfen, ob auch kleinere Mengen von Solidi in bestimmten Gewichtseinheiten (und in entsprechenden Beuteln) aufbewahrt oder verhandelt wurden,

74 Wolfgang Hahn, Moneta Imperii Byzantini 1: Von Anastasius I. bis Justinianus I. (491-565) (Österreichische Akademie der Wissenschaften Phil.-Hist. Klasse Denkschriften 109) Wien 1973, S. $24 \mathrm{ff}$,

75 Iluk (wie Anm. 51) S. 85.

76 Vgl. oben nach Anm. 51.

$77 \mathrm{Da}$ in den 440er Jahren weitere Münzwerkstätten nebst der konstantinopolitanischen an der Ausprägung von Sonderemissionen für die Tribute an die Hunnen - ein zusätzlicher Beweis, daß Solidi geliefert wurden - beteiligt waren, zeigt WolfGang HahN, Die östliche Gold- und Silberprägung unter Theodosius II. (Litterae numismaticae Vindobonenses Roberto Goebl dedicatae, Wien 1979 , S. $103-128$ ) bes. S. $113 \mathrm{ff}$. 
TABELLE 7:

ANZAHL DER SOLIDI IN GESCHLOSSENEN MÜNZHORTEN DES 4.

UND 5. JAHRHUNDERTS N. CHR.

(vgl. Anm. 76)

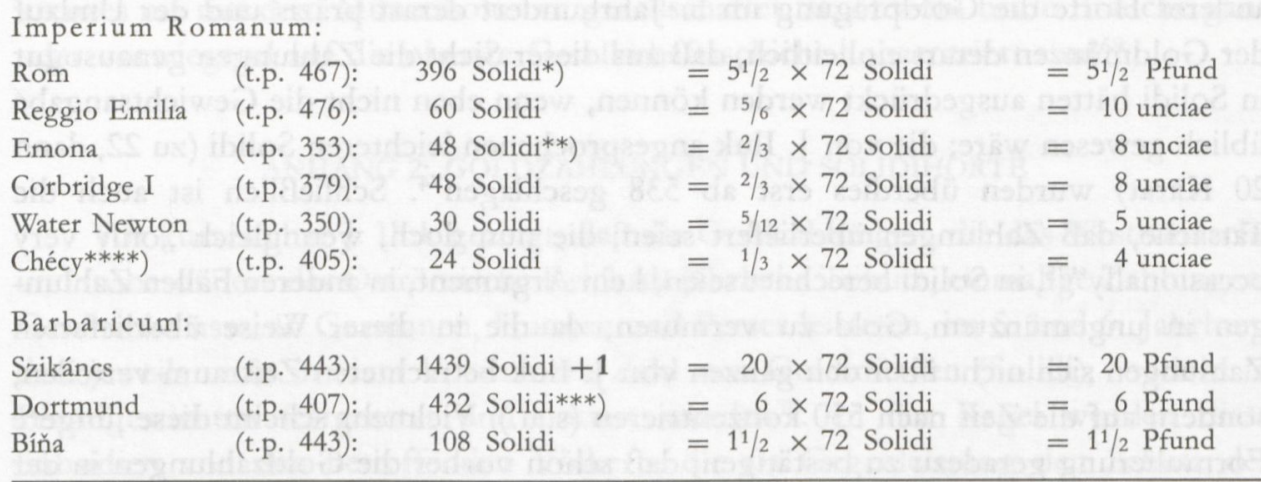

*) ohne einen der Münzreihe um über 80 Jahre vorangehenden, isolierten Solidus des Constantius II. aus dem Jahre 343.

**) ohne einen Aureus und einen $1 \frac{1}{4} 4$ Solidus.

***) ohne 12 gelochte Solidi.

****) fraglich, ob vollständig.

können Hortfunde von Solidi herangezogen werden. Ein Großteil davon ist allerdings wegen zufälliger Entdeckung unvollständig auf uns gekommen; andere dürften aus individuellen Gründen eine ungerade, z. B. dem momentanen Besitz entsprechende Anzahl von Solidi enthalten. Von den in Tabelle 7 vereinigten Hortfunden des 5 . Jahrhunderts ${ }^{78}$ sind gleich zwei der drei im Barbaricum gelegenen Horte aufschlußreich: In Bíňa (Slowakei) fanden sich bei einer Ausgrabung in einem Topf 108 Solidi, d. h. 1 Pfund und 6 Unzen Gold. In Szikáncs kamen zufällig, aber mit systematischer Nachkontrolle insgesamt 1439 (von ursprünglich wohl 1440) Solidi zutage, also 20 Pfund Gold, wie bereits K. Biró-Sey bei der Publikation

78 Nachweise zu den in Tabelle 7 angeführten Hortfunden:

Imperium Romanum: Rom: G. BonI (Atti della Accademia nazionale dei Lincei CCCL Rendiconti 8, 1-2, Rom 1953, S. 327-330). - Reggio Emilia: Bierbrauer (wie Anm. 37, 1975) S. 202 ff., 304. - Emona: Walter Schmid, Ein Fund von Goldmünzen und Silberbarren (Jahrbuch für Altertumskunde 7, 1913, S. 171-179). - Corbridge I: H. A. Grueber (Numismatic Chronicle Ser. 4, 13 [1913] S. 31-56). - Water Newton: Catherine M. Johns - R. A. G. Carson, The 1974 Water Newton Hoard (Kenneth S. Painter, The Water Newton Early Christian Silver, London 1977) S. 27 f. - Chécy: Jean Lafaurie, Trésors monétaires et plaques-boucles de la Gaule romaine (Gallia XXI ${ }^{e}$ supplément) Paris 1958, S. 22 ff.

Barbaricum: Szikáncs: Katalin Biró-SEY (Numizmatikai Közlöny [Budapest] 74/75, 1975/76, S. 7-19). Zu den Fundumständen DiEs., Der frühbyzantinische Solidus-Fund von Szikáncs (Jahrbuch der Staatlichen Kunstsammlungen Dresden 1970/71, S. 177-186) S. 177; HaHN (wie Anm. 77) S. 122. - Dortmund: Peter Berghaus, Dortmund (Fund römischer Goldmünzen) (Reallexikon der Germanischen Altertumskunde 6, 21985, S. 124-127 [mit Lit.]). - Bíňa: Eva KolníkovÁ (Numismatický Sborník 10, 1967/68, S. 5-50); НАнN (wie Anm. 77) S. 123. - Vgl, zur Goldmenge dieser Horte jetzt auch Hans-Rudolf Meier (Schweizerische Numismatische Rundschau 65, 1986, S. 133-151) bes. S. 141. 
des Fundes bemerkte ${ }^{79}$. An beiden Orten wurde offenbar eine bestimmte Zahl von Solidi, besser gesagt ein bestimmtes Gewicht Gold, sei es als Opfergabe, wie vermutlich in Szikáncs, oder aus anderen Gründen im Boden vergraben. Ob auch in Dortmund wirklich 6 Pfund Gold versteckt wurden, bleibt hingegen wegen der Fundumstände etwas unsicher. Auch im Innern des Imperium Romanum wurde selbstverständlich Gold von einer gewissen Menge an in der Regel nicht ungezählt bzw. ungewogen aufbewahrt oder vergraben, wie die in der Tabelle angeführten, sicher vollständig geborgenen Horte aus Rom und Reggio Emilia erkennen lassen.

Aus J. Iluks Zusammenstellungen geht hervor, daß nach der Mitte des 6 . Jahrhunderts Zahlungen des byzantinischen Staates kaum mehr in Kentenarien bzw. Pfundgewichten, sondern in runden Solidizahlen - vor 550 kam solches nur als Ausnahme vor - geleistet oder, vorsichtiger gesagt, in den Schriftquellen verzeichnet wurden: 555 waren es 28'800 Solidi (= 400 Pfund Gold), 561/62 30'000 Solidi, 574 80’000 Solidi, 575 30’000 Solidi usw. Dasselbe Bild bietet die spärlichere Überlieferung im Westen: Während etwa Alarich 408 bzw. 410 von Rom noch 4000 bzw. 5000 Pfund Gold und 30'000 Pfund Silber erhielt, 536 Witigis den Franken 2000 Pfund Gold zahlte und noch 577/78 der Senat von Rom mit 3000 Pfund Gold von Byzanz Hilfe erlangen wollte ${ }^{80}$, überwiegen seit der zweiten Hälfte des 6. Jahrhunderts, bei Gregor von Tours und Fredegar, für Goldzahlungen Angaben wie $50^{\prime} 000,36^{\prime} 000$ (= 500 Pfund Gold), 12’000, 7000, 1000 Solidi usw. ${ }^{81}$. Da seit 538 im Osten, wie bereits erwähnt, nebst vollgewichtigen Solidi (zu 24 Karat) auch 22-karätige und bald auch 20 -karätige geschlagen wurden und auch im Westen Solidi von verschiedenem Gewicht im Umlauf waren, wären eigentlich eher jetzt Gewichtsangaben für Goldmengen zu erwarten (und für uns heute von Nutzen) als für das 5. und frühere 6. Jahrhundert, als eine bestimmte Zahl von Solidi noch einem bestimmten Gewicht Gold entsprach.

Auch in den Leges der germanischen Stämme sind übrigens, anders als noch im Codex Theodosianus, Bußen und vor allem natürlich die Wergelder stets in Geldsummen, in runden Solidizahlen festgesetzt. Bereits in der spätestens um 500

79 Biró-Sey (wie Anm. 78, 1975/76) S. 19, allerdings aus dem Gesamtgewicht des Fundes (6,446 kg, statt 6,549 kg bei einem Pfundgewicht von 327,45 g) abgeleitet, nicht aus der Anzahl der Solidi. Das Durchschnittsgewicht einzelner großer Prägeserien in diesem Fund schwankt nur geringfügig zwischen 4,493 und 4,501 g: So wiegen z. B. 902 Exemplare einer gleichen Emission im Mittel 4,497 g; von diesen 902 Münzen sind 855, d. h. 94,8\% zwischen 4,48 $\mathrm{g}$ und 4,52 $\mathrm{g}$ schwer und lassen auf eine Gewichtstoleranz von $\pm 0,02 \mathrm{~g}$ bei der Prägung schließen. Wegen der prägefrischen Erhaltung der Münzen und der äußerst präzisen Justierung möchte ich vermuten, daß damals statt Solidi zu 24 Karat (4,548 g) minim reduzierte Solidi zu 233/4 Karat (4,5005 g) angeordnet und geschlagen wurden, ohne daß diese kaum feststellbare Reduktion um 1/96 $(0,047 \mathrm{~g})$, d. h. um 1,04\% des Vollgewichts - auf 1440 Solidi, d. h. auf 20 Pfund Gold ergab sich eine Reduktion von 68,2 g offiziell auf der Münze markiert worden wäre: MArtin (wie Anm. 3).

80 Ludwig Schmidt, Die Ostgermanen, München 21969, S. 442 f., 598; Herwig Wolfram, Geschichte der Goten, München 21980, S. 182 f., 185, 423.

81 Claude (wie Anm. 47) S. 11 f.; Margarete Weidemann, Kulturgeschichte der Merowingerzeit nach den Werken Gregors von Tours, Teil 2 (Monographien des Römisch-Germanischen Zentralmuseums Mainz 3,2) Mainz 1982, S. 345 f.; ebd. S. 339 wird das auch bei Gregor von Tours, aber stets im Zusammenhang mit dem byzantinischen Kaiserhaus genannte centenarium - kaum zu Recht - als Gewicht für ungemünztes Edelmetall bezeichnet. 
erlassenen Lex Visigothorum finden sich Sätze zu 300, 200, 150, 100 und 20 Solidi, ebenso in der etwa zeitgenössischen Lex Burgundionum.

Zusammenfassend läßt sich festhalten, daß während des ganzen 5. und früheren 6. Jahrhunderts gemünztes Gold, das ins Barbaricum und damit auch in die Germania libera gelangte, nach dem römischen Gewichtssystem abgewogen war und von den Barbaren sicher auch auf dieses Gewicht kontrolliert wurde. Welche Gründe hinter den erst im Laufe des 6. Jahrhunderts üblich werdenden Angaben von runden Solidizahlen stehen, bleibt unklar und kann hier nicht erörtert werden.

\section{NACHTRAG}

Erst beim Lesen der letzten Korrektur fiel mir auf, daß das von J. Werner (wie Anm. 2) errechnete (und von mir übernommene) Gesamtgewicht der 37 Trienten („40,0032 g“) falsch ist und richtig 47,0026 g (Gesamtgewicht der 42 Objekte: 61,1115 g) beträgt, weshalb die S. 206 f. zu Redwalds Börse gemachten Angaben nicht in ihrem Ergebnis, wohl aber hinsichtlich Anzahl der Unzen - und nur darin - zu korrigieren sind:

Das Gesamtgewicht der 37 Trienten und 3 „Schrötlinge“ $(47,0026 \mathrm{~g}+3,9281 \mathrm{~g}=50,9307 \mathrm{~g})$ beträgt exakt das Fünffache des Gewichts der zwei Barren $(10,1808 \mathrm{~g})$, so daß wir insgesamt eine Goldmenge vor uns haben, die $40+8=48$ Trienten (im folgenden auch so bezeichnet) entspricht.

Wie auch andere Funde zeigen, bildeten im 7. Jahrhundert nicht Solidi, sondern (reduzierte) Trienten sozusagen die alleinige Münzeinheit in Gold. Um auf das Pfund (1728 Siliquae) eine ganze Zahl - conditio sine qua non - an Trienten zu erhalten, kann das Gewicht dieser reduzierten Merowingertrienten nicht, wie in der Numismatik wegen der Aufschrift VII angenommen wird, wirklichen vollen 7 Siliquae (was aufs Pfund 246,857 Trienten zu 1,3265 g ergäbe) entsprochen haben, sondern muß 63/4 (inschriftlich „VII“) Siliquae betragen, womit aufs Pfund 256 Trienten zu 1,2791 g kommen; diesem Gewicht entspricht das Mittel der 37 bzw. 48 Trienten in Sutton Hoo (47,0026 g: $37=1,2703 \mathrm{~g}$ bzw. $61,1115 \mathrm{~g}: 48=1,2732 \mathrm{~g}$ ) aufs beste. Da 256 nicht durch 12 teilbar ist, konnten zur Aufteilung und Aufbewahrung nach dem Unzialsystem nicht mehr Einheiten zu 1 Unze gebildet werden. In Sutton Hoo werden die 48 Trienten $(=3 / 16$ von 256 Trienten) in einem Beutel zu 32 Trienten $\left(=1 / 8\right.$ Pfund $=1 \frac{1}{2}$ Unzen $)$ und einem Beutel zu 16 Trienten $(=1 / 16$ Pfund $=3 / 4$ Unze $)$ oder in drei dieser kleineren Beutel gelegen haben; ihr Gesamtgewicht $(61,1115 \mathrm{~g})$ beträgt $99,5 \%$ von $1 \frac{1}{2}+3 / 4$ Unzen $(61,3969 \mathrm{~g})$.

Die „Schrötlinge“, m.E. in münzähnliche Form gebrachte Kleinstbarren, und die Barren dienten dort als Ausgleichsgewichte, wo das stets geforderte, ins Unzialsystem passende Normgewicht eines Beutels zu $1 / 16,1 / 8,1 / 4,1 / 2$ Pfund usw. (nicht aber eben zu $1 / 12,1 / 6$ oder $1 / 3$ Pfund) nicht anders zu bilden war.

Wie die auch in anderen Trientenhorten vorkommenden (mitunter münzähnlichen) Kleinstbarren mit ihren „erratic weights“ (KeNT [wie Anm. 1] S. 605) durch ihre Existenz und Funktion beweisen, wurde auch damals Gold in unziale Gewichtseinheiten gebracht und derart aufbewahrt und verhandelt; diese wurden nun allerdings so festgesetzt, daß sie durch reduzierte Trienten einfach zu bilden waren. Allein die auf reduzierten Trienten basierende Goldwährung der jüngeren Merowingerzeit ist die Ursache für den auf den ersten Blick mit seinen $2 \frac{1}{4}$ (statt 2) Unzen nicht ins Unzialsystem passenden Börseninhalt Redwalds. 


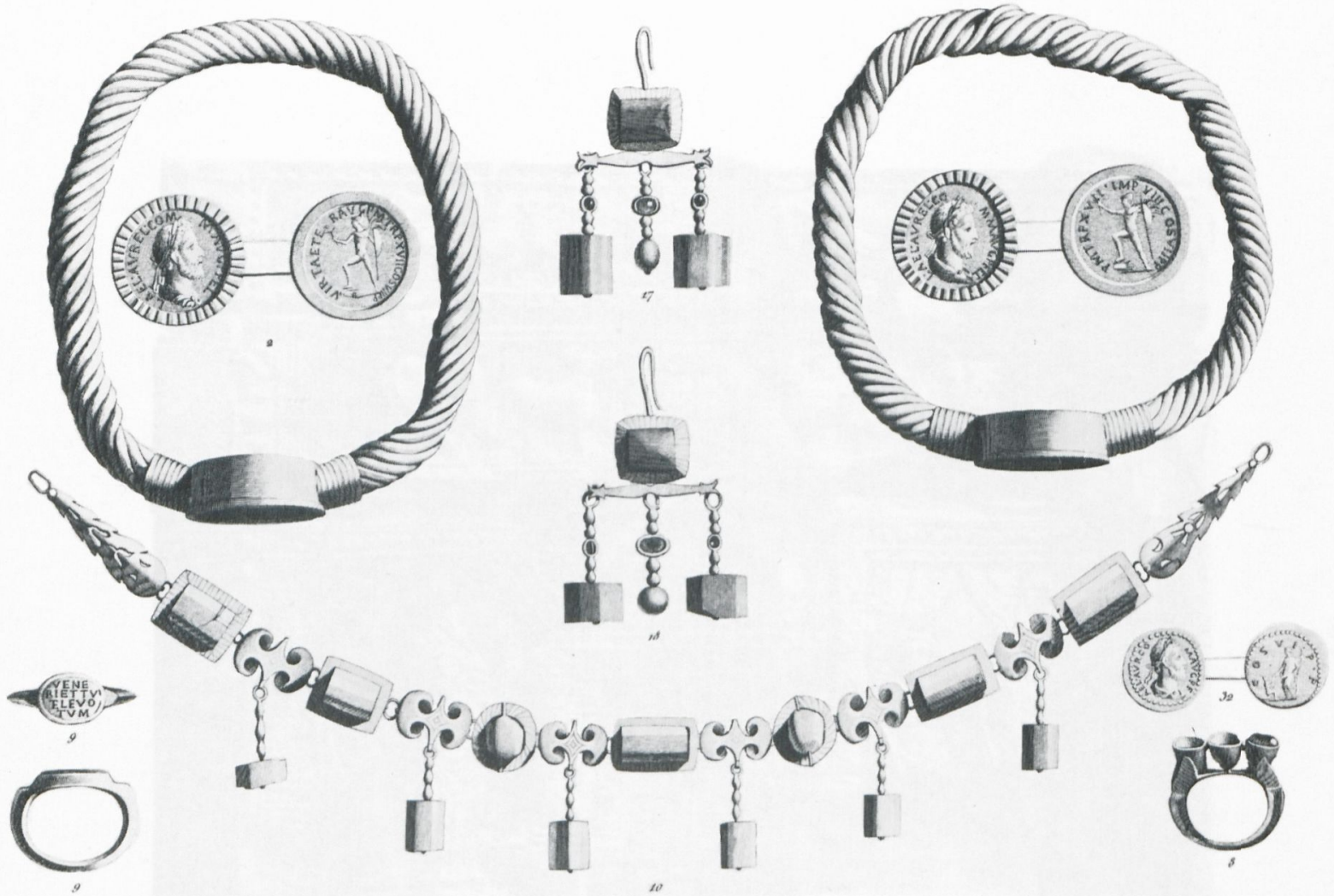

56 Teile eines vermutlich im Jahre 197 n. Chr. in Lyon vergrabenen Schmuckhortes, darunter zwei goldene Armbänder zu je 6 Unzen Gewicht. Nach A. Comarmond, 1844, Taf. 1; vgl. Tabelle 1.
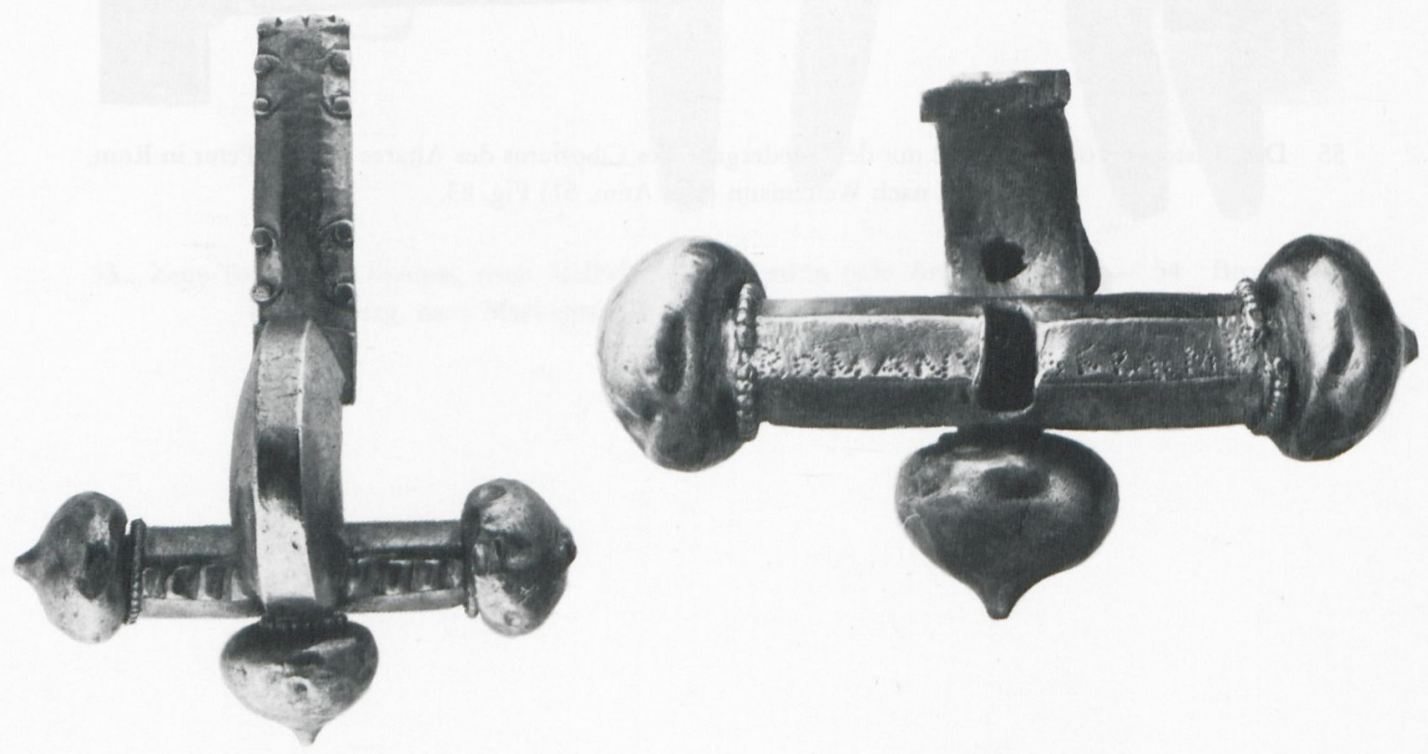

57 Goldene Zwiebelknopffibel aus dem Hortfund von Lengerich, Kr. Emsland. 1:1 (Detail mit Inschrift vergrößert). (Fotos Niedersächsisches Landesmuseum Hannover) 